\title{
ONREL
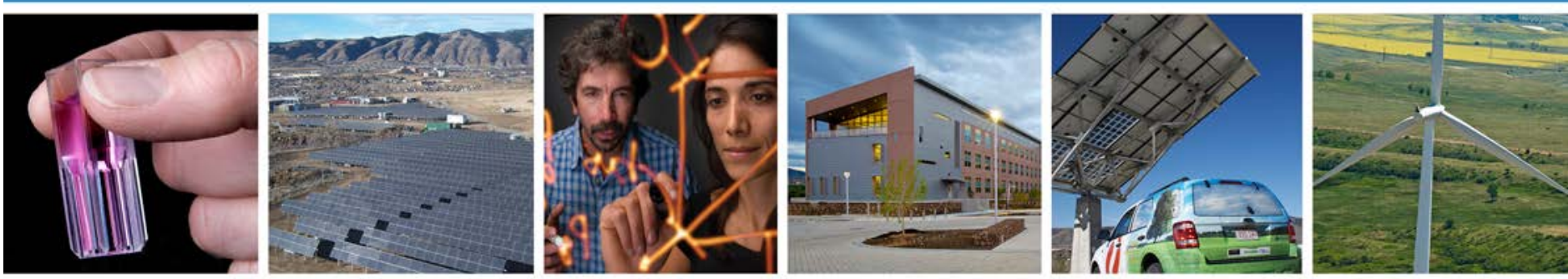

\section{Evaluation of Air Mixing and Thermal Comfort From High Sidewall Supply Air Jets}

\author{
El Hassan Ridouane
}

NREL is a national laboratory of the U.S. Department of Energy, Office of Energy Efficiency \& Renewable Energy, operated by the Alliance for Sustainable Energy, LLC.

Technical Report

NREL/TP-5500-48664

September 2011 


\section{Evaluation of Air Mixing and Thermal Comfort From High Sidewall Supply Air Jets}

\section{El Hassan Ridouane}

Prepared under Task No. BE11.0102 


\section{NOTICE}

This report was prepared as an account of work sponsored by an agency of the United States government. Neither the United States government nor any agency thereof, nor any of their employees, makes any warranty, express or implied, or assumes any legal liability or responsibility for the accuracy, completeness, or usefulness of any information, apparatus, product, or process disclosed, or represents that its use would not infringe privately owned rights. Reference herein to any specific commercial product, process, or service by trade name, trademark, manufacturer, or otherwise does not necessarily constitute or imply its endorsement, recommendation, or favoring by the United States government or any agency thereof. The views and opinions of authors expressed herein do not necessarily state or reflect those of the United States government or any agency thereof.

Available electronically at http://www.osti.gov/bridge

Available for a processing fee to U.S. Department of Energy and its contractors, in paper, from:

U.S. Department of Energy

Office of Scientific and Technical Information

P.O. Box 62

Oak Ridge, TN 37831-0062

phone: 865.576 .8401

fax: 865.576 .5728

email: mailto:reports@adonis.osti.gov

Available for sale to the public, in paper, from:

U.S. Department of Commerce

National Technical Information Service

5285 Port Royal Road

Springfield, VA 22161

phone: 800.553 .6847

fax: 703.605.6900

email: orders@ntis.fedworld.gov

online ordering: http://www.ntis.gov/help/ordermethods.aspx

Cover Photos: (left to right) PIX 16416, PIX 17423, PIX 16560, PIX 17613, PIX 17436, PIX 17721

Printed on paper containing at least $50 \%$ wastepaper, including $10 \%$ post consumer waste. 


\section{Nomenclature}

$\mathrm{ACH} \quad$ Air changes per hour

ADPI Air diffusion performance index

$\mathrm{A}_{\mathrm{c}} \quad$ Room ceiling area, $\mathrm{ft}^{2}$

$\mathrm{A}_{\mathrm{f}} \quad$ Room floor area, $\mathrm{ft}^{2}$

$\mathrm{A}_{\mathrm{w}} \quad$ Exterior wall area, $\mathrm{ft}^{2}$

$\mathrm{A}_{\mathrm{o}} \quad$ Area of supply inlet, $\mathrm{ft}^{2}$

CFD Computational fluid dynamics

PMV Predicted mean vote

PPD Predicted percentage of dissatisfied

$\ddot{q}_{c} \quad$ Ceiling heat flux, Btu $/ \mathrm{h} \cdot \mathrm{ft}^{2}$

$\ddot{q}_{l d} \quad$ Room load density, Btu/h$\cdot \mathrm{ft}^{2}$

$\ddot{q}_{w} \quad$ Exterior wall heat flux, Btu/h$\cdot \mathrm{ft}^{2}$

$q_{t} \quad$ Total heat transfer rate into the room, Btu/h

Q flow rate from supply inlet, cfm

$R_{c} \quad$ Ceiling R-value, $\mathrm{ft}^{2} \cdot \mathrm{h} \cdot{ }^{\circ} \mathrm{F} / \mathrm{Btu}$

$R_{w} \quad$ Exterior wall R-value, $\mathrm{ft}^{2} \cdot \mathrm{h} \cdot{ }^{\circ} \mathrm{F} / \mathrm{Btu}$

SHGC Solar heat gain coefficient

$\mathrm{T}_{\mathrm{S}} \quad$ Supply air temperature, ${ }^{\circ} \mathrm{F}$

$\mathrm{T}_{\text {set }} \quad$ Thermostat set point, ${ }^{\circ} \mathrm{F}$

$\mathrm{V}_{\mathrm{S}} \quad$ Supply air velocity, fpm

$\mathrm{V}_{\mathrm{x}} \quad$ Local air velocity, fpm

$\mathrm{X} \quad$ Throw of the inlet jet, $\mathrm{ft}$

$\theta \quad$ Effective draft temperature, ${ }^{\circ} \mathrm{F}$

\section{Acknowledgments}

The author thanks Ren Anderson for his guidance and for his valuable contributions to this report. 


\section{Executive Summary}

Effective mixing of conditioned air with room air is an essential factor for providing uniform comfort in homes. The higher the supply air flow rates, the easier it is to reach good mixing within the space. In high performance homes, however, the flow rates required to meet the small remaining thermal loads may not be large enough to maintain uniform mixing in the space.

The objective of this study is to evaluate operating conditions required to maintain uniform mixing, within high performance homes, under both heating and cooling conditions. This can be achieved by creating proper combination of temperature and air motion in the occupied zone of the conditioned space. Lack of uniform conditions in the space or excessive fluctuation of conditions produces discomfort. Discomfort can be caused by excessive air motion (draft), excessive room air temperature variations, or failure to deliver or distribute air according to load requirements.

To address this question we used computational fluid dynamics modeling to evaluate the performance of high sidewall air supply for residential applications in heating and cooling modes. Parameters that were varied in the study include the supply velocity, supply temperature, and inlet dimensions. The model provided high resolution velocity and temperature distributions in the room, which were used to determine the effective draft temperature. The latter is then used to calculate the Air Diffusion Performance Index (ADPI). This parameter was used to evaluate the air distribution and thermal comfort in the occupied zone. ADPI is the percentage of locations where the effective draft temperature and air speed meet comfort specifications. The higher the ADPI value is, the more comfortable the space will be for most occupants.

The results provide information to guide the selection of high sidewall air supply inlets to maintain proper room mixing for heating and cooling of high performance homes. It is demonstrated that these systems can achieve good mixing and provide acceptable comfort levels. Recommendations are given for the operating conditions to guarantee occupant comfort. 


\section{Contents}

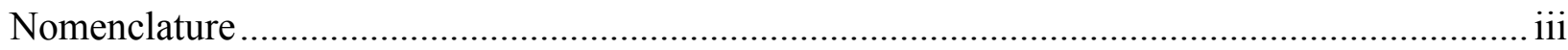

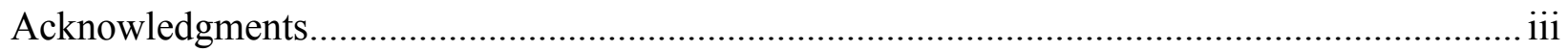

Executive Summary ..................................................................................................... iv

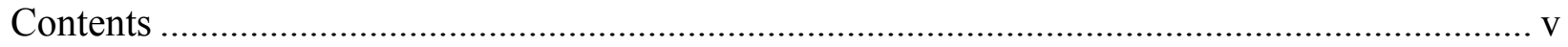

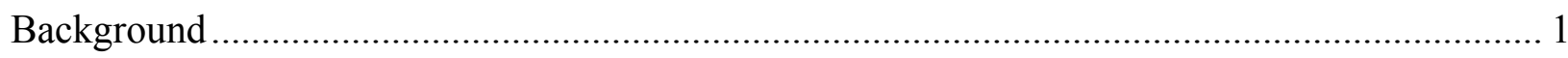

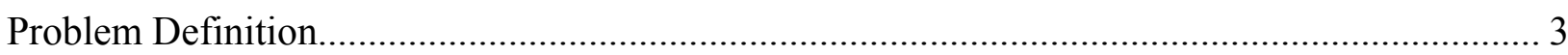

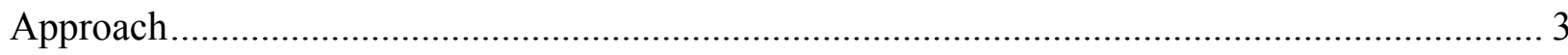

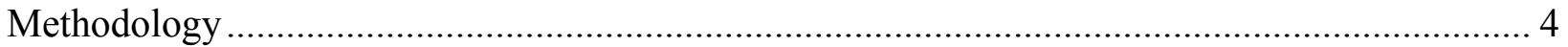

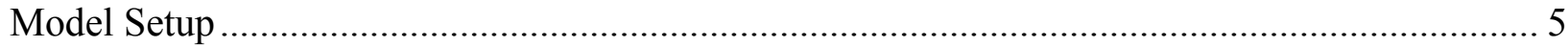

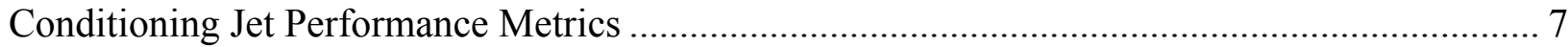

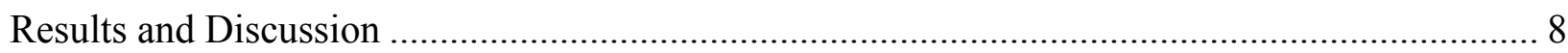

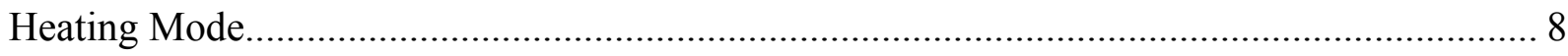

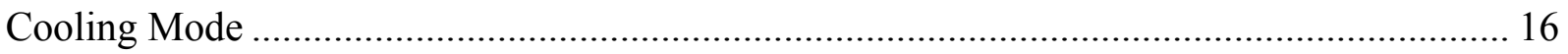

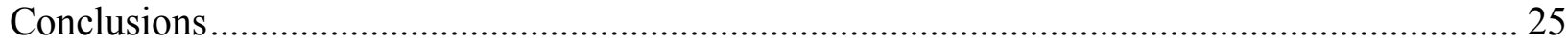

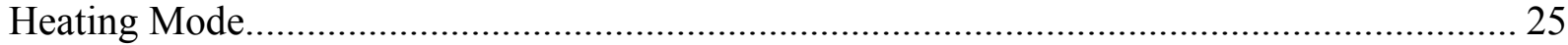

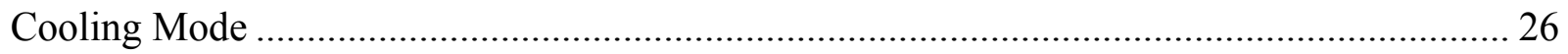

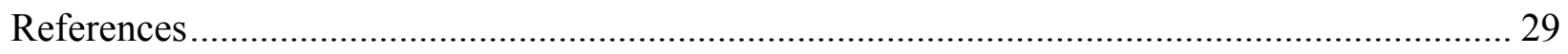

\section{Tables}

Table A. Reference house construction type and assumptions used to calculate loads.................. 4

Table B. Recommended System Operating Conditions ………................................................. 28 


\section{Figures}

Figure 1. Sketch of the computational domain (not to scale) showing the locations of supply, return, and thermostat in the room. Thermal loads are applied only to the ceiling and to the right wall to approximate load distributions in a perimeter zone.

Figure 2. Time history of air temperature near the thermostat (a) and velocity at the inlet (b) from an $8 \times 1$ inlet when supplied by $\mathrm{T}_{\mathrm{s}}$ of $120^{\circ} \mathrm{F}(322 \mathrm{~K})$

Figure 3. Air temperature near the thermostat (a) and velocity at the inlet from an $8 \times 4$ inlet (b) as a function of time when supplied by $\mathrm{T}_{\mathrm{s}}$ of $120^{\circ} \mathrm{F}(322 \mathrm{~K})$.

Figure 4. Temperature distribution at the symmetry plane of the room with an $8 \times 4$ inlet when supplied by $\mathrm{T}_{\mathrm{s}}$ of $120^{\circ} \mathrm{F}(322 \mathrm{~K})$ : (a) $\mathrm{V}_{\mathrm{s}}=558 \mathrm{fpm}(2.83 \mathrm{~m} / \mathrm{s})$ and (b) $\mathrm{V}_{\mathrm{s}}=714 \mathrm{fpm}(3.62 \mathrm{~m} / \mathrm{s}) 11$

Figure 5. Temporal evolution of air temperature near the thermostat (a) and supply velocity at the inlet (b) of the room with $8 \times 4$ inlet when supplied by two different temperatures, $95^{\circ} \mathrm{F}(308 \mathrm{~K})$

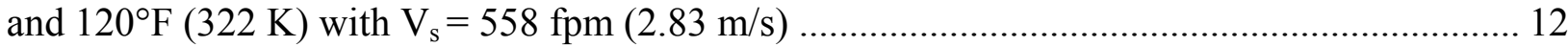

Figure 6. Temperature distribution in the room, with an $8 \times 4$ supply inlet, at 1 air change when supplied by $\mathrm{T}_{\mathrm{s}}$ of $95 \mathrm{~F}(308 \mathrm{~K})$ : (a) $\mathrm{V}_{\mathrm{s}}=214 \mathrm{fpm}(1.1 \mathrm{~m} / \mathrm{s})$, (b) $\mathrm{V}_{\mathrm{s}}=558 \mathrm{fpm}(2.83 \mathrm{~m} / \mathrm{s})$, and (c) $\mathrm{V}_{\mathrm{s}}=714 \mathrm{fpm}(3.62 \mathrm{~m} / \mathrm{s})$. Left plots are at the symmetry plane and right plots are at different cross sections throughout the room.

Figure 7. Distribution of draft temperature in the room, with an $8 \times 4$ inlet, when $\mathrm{T}_{\mathrm{S}}=95^{\circ} \mathrm{F}(308$ $\mathrm{K})$ : (a) $\mathrm{V}_{\mathrm{S}}=214 \mathrm{fpm}(1.1 \mathrm{~m} / \mathrm{s}),(\mathrm{b}) \mathrm{V}_{\mathrm{S}}=558 \mathrm{fpm}(2.83 \mathrm{~m} / \mathrm{s})$, and (c) $\mathrm{V}_{\mathrm{S}}=714 \mathrm{fpm}(3.62 \mathrm{~m} / \mathrm{s})$. Top row shows the draft temperature at full scale and the bottom row shows acceptable draft temperature, between -3 and $2^{\circ} \mathrm{F}$.

Figure 8. Temporal evolution of air temperature near the thermostat and the supply velocity at the $10 \times 6$ inlet when the room is supplied by $\mathrm{V}_{\mathrm{s}}=329 \mathrm{fpm}(1.67 \mathrm{~m} / \mathrm{s})$ and $\mathrm{T}_{\mathrm{s}}=95^{\circ} \mathrm{F}(308 \mathrm{~K}) \ldots 15$

Figure 9. Temperature distribution in the room, with a $10 \times 6$ inlet, at 1 air change when supplied by $\mathrm{T}_{\mathrm{s}}$ of $95^{\circ} \mathrm{F}(308 \mathrm{~K})$ : (a) $\mathrm{V}_{\mathrm{s}}=329 \mathrm{fpm}(1.67 \mathrm{~m} / \mathrm{s})$ and (b) $\mathrm{V}_{\mathrm{s}}=788 \mathrm{fpm}(4 \mathrm{~m} / \mathrm{s})$. Left plots are at the symmetry plane and right plots are at different cross sections throughout the room ......... 16

Figure 10. Temporal evolution of air temperature near the thermostat (a) and supply velocity at the inlet (b) of the room with $8 \times 1$ inlet when supplied by two different velocities, $591 \mathrm{fpm}$ (3 $\mathrm{m} / \mathrm{s})$ and $788 \mathrm{fpm}(4 \mathrm{~m} / \mathrm{s})$ with $\mathrm{T}_{\mathrm{s}}=55^{\circ} \mathrm{F}(286 \mathrm{~K})$

Figure 11. Temperature distribution in the room, with an $8 \times 1$ inlet, at 1 air change when supplied by $\mathrm{T}_{\mathrm{s}}$ of $55^{\circ} \mathrm{F}(286 \mathrm{~K})$ : (a) $\mathrm{V}_{\mathrm{s}}=591 \mathrm{fpm}(3 \mathrm{~m} / \mathrm{s})$ and (b) $\mathrm{V}_{\mathrm{s}}=788 \mathrm{fpm}(4 \mathrm{~m} / \mathrm{s})$. Left plots are at the symmetry plane and right plots are at different cross sections along the room.

Figure 12. Temporal evolution of air temperature near the thermostat (a) and supply velocity at the inlet (b) of the room with $8 \times 4$ inlet when supplied by two different velocities, $394 \mathrm{fpm}(2$ $\mathrm{m} / \mathrm{s})$ and $591 \mathrm{fpm}(3 \mathrm{~m} / \mathrm{s})$ with $\mathrm{T}_{\mathrm{s}}=55^{\circ} \mathrm{F}(286 \mathrm{~K})$

Figure 13. Temperature distribution at the symmetry plane of the room, with an $8 \times 4$ inlet, when $\mathrm{V}_{\mathrm{s}}=788 \mathrm{fpm}(4 \mathrm{~m} / \mathrm{s})$ and $\mathrm{T}_{\mathrm{s}}=55^{\circ} \mathrm{F}(285.9 \mathrm{~K})$.

Figure 14. Temperature distribution in the room, with an $8 \times 4$ inlet, at 1 air change when supplied by $\mathrm{V}_{\mathrm{s}}=591 \mathrm{fpm}(3 \mathrm{~m} / \mathrm{s})$ : (a) $\mathrm{T}_{\mathrm{S}}=55^{\circ} \mathrm{F}(285.9 \mathrm{~K})$ and (b) $\mathrm{T}_{\mathrm{S}}=65^{\circ} \mathrm{F}(291.5 \mathrm{~K}) \ldots \ldots \ldots \ldots \ldots \ldots \ldots \ldots . . .21$ 
Figure 15. Distribution of draft temperature in the room, with an $8 \times 4$ inlet, when $\mathrm{T}_{\mathrm{S}}=55^{\circ} \mathrm{F}$ (285.9 K): (a) $\mathrm{V}_{\mathrm{S}}=394 \mathrm{fpm}(2 \mathrm{~m} / \mathrm{s})$, (b) $\mathrm{V}_{\mathrm{S}}=591 \mathrm{fpm}(3 \mathrm{~m} / \mathrm{s})$, and (c) $\mathrm{V}_{\mathrm{S}}=788 \mathrm{fpm}(4 \mathrm{~m} / \mathrm{s})$. Top row shows the draft temperature at full scale and the bottom row shows the acceptable draft

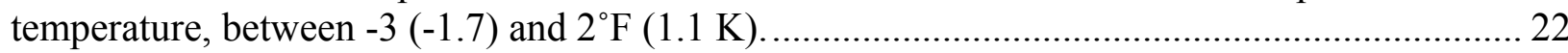

Figure 16. Temporal evolution of air temperature near the thermostat when the room is supplied by a $10 \times 6$ inlet at $\mathrm{V}_{\mathrm{s}}=788 \mathrm{fpm}(4 \mathrm{~m} / \mathrm{s})$

Figure 17. Temperature distribution $(\mathrm{a}-\mathrm{c})$ and velocity vectors $(\mathrm{d})$ at the symmetry plan of the room, with a $10 \times 6$ inlet: (a) $\mathrm{V}_{\mathrm{S}}=329 \mathrm{fpm}(1.67 \mathrm{~m} / \mathrm{s})$, (b) $\mathrm{V}_{\mathrm{S}}=558 \mathrm{fpm}(2.83 \mathrm{~m} / \mathrm{s})$, and (c-d) $\mathrm{V}_{\mathrm{S}}$ $=788 \mathrm{fpm}(4 \mathrm{~m} / \mathrm{s})$. The supply temperature is $55^{\circ} \mathrm{F}(285.9 \mathrm{~K})$. 24

Figure 18. Capacity of different systems relative to peak load in heating mode: (a) $8 \times 1$ inlet, (b) $8 \times 4$ inlet, and (c) $10 \times 6$ inlet.

Figure 19. Variations of ADPI as a function of supply velocity in heating mode: (a) $8 \times 1$ inlet, (b) $8 \times 4$ inlet, and (c) $10 \times 6$ inlet...... 26

Figure 20. Capacity of different systems relative to peak load in cooling mode: (a) $8 \times 1$ inlet, (b) $8 \times 4$ inlet, and (c) $10 \times 6$ inlet.

Figure 21. Variations of ADPI as a function of supply velocity in cooling mode: (a) $8 \times 1$ inlet, (b) $8 \times 4$ inlet, and (c) $10 \times 6$ inlet. 28

All figures in this report were produced by NREL employees. 


\section{Background}

Understanding indoor air distribution and the draft risk in the occupied zone are essential to the design of HVAC systems. Thermal comfort of occupants is directly affected by indoor air velocity. Therefore air velocity is specified in the common thermal comfort indices such as the predicted mean vote (PMV), the predicted percentage of dissatisfied (PPD), and the air diffusion performance index (ADPI) (Chow and Wong, 1994). Evaluation of the location where the jet enters the room is also necessary to minimize the draft risk (Corgnati et al., 2002).

Numerous studies were carried out in the past two decades to predict indoor airflow patterns using two main approaches: experimental investigation and numerical calculation. Experimental models have been widely used for predicting air distribution performance in buildings. Chow and Wong (1994) studied the air speed induced by a diffuser in an environmental chamber under different flow conditions. The measurements showed no obvious correlation between ADPI and the supply flow rate. The diffuser throw was found to be linearly related to the Archimedes number, which represents the ratio of buoyancy to inertial force exerted on the fluid. Yu et al. (2007) studied airflow in a ceiling slot-ventilated enclosure in a 1:3 scale model. They measured the velocity and temperature profiles, temperature decays, and thermal boundary layers. The data was used to develop empirical models. Zang et al. (2009) used an environmental chamber to mimic a section of an airliner cabin. The experimental model used tracer gas and particles for contaminant transport simulation. The experiment approximated thermo-fluid boundary conditions and simulated passengers by heated boxes. Ultrasonic anemometers were used to measure the air velocity, temperature distribution, and contaminants concentration.

Full scale experimental models limit simplifying assumptions associated with small scale and analytical models. However, they are generally expensive and time consuming and can not easily cover all possible operating conditions. There is a growing trend that consists of using laboratory experiments to obtain data to validate computer models, and then use the validated models to predict ventilation performance or design of HVAC systems (Chen, 2009). Corgnati et al. (2009) performed a numerical study in cooling mode, using CFD, which was validated against experimental data from a full scale test room, simulating a typical two-desk office. The numerical study was then extended to couple mixing ventilation and cold radiant ceiling panels. The results showed that the use of coupled systems led to an increase in the jet throw and to a significant decrease of the draft risk.

Pure numerical studies were most popular and dominate the research literature in the past decade. CFD models in particular have been widely used to study indoor air distribution, air quality, thermal comfort, and HVAC system performance. Norton et al. $(2006,2007)$ conducted reviews of CFD applications for ventilation studies in food and agricultural industry such as green houses and animal production facilities. Three different air diffusion models were investigated by Chung and Lee (1996) in cooling mode. These include a room with one inlet one outlet, two inlets - one outlet, and one inlet - two outlets. Evaluation of thermal comfort is made in terms of the percentage dissatisfied (PD) and the air diffusion performance index (ADPI). Variations of PD and ADPI with the inlet velocity and temperature showed that a higher PD or lower ADPI is associated with a higher velocity and lower inlet temperature. This study also underscores the importance of inlet/outlet locations for evaluating indoor thermal comfort. 
CFD program EXACT3 has been used by Lam and Chan (2001) to analyze the temperature distribution and air movement within an air-conditioned gymnasium. Different exhaust positions were considered, sharing one inlet located high on a sidewall. The effects of thermal stratification on the energy performance were examined with respect to the HVAC plant oversizing issue. The smallest cooling load requirement was found in the configuration with ceiling exhaust. This configuration was identified, in terms of energy efficiency, as the best design arrangement. CFD models have also been used to improve other building simulation tools so that ventilation performance can be more accurately predicted (Chen, 2009). Wang and Chen (2007) coupled CFD with a multizone airflow program to improve the prediction of airflow and contaminant in an entire building.

This study evaluates the thermal performance of high sidewall inlet jets in heating and cooling modes using CFD. The three dimensional model considers a single room in a high performance home and evaluates the thermal comfort as a function of operating conditions. This report describes details of the numerical model, discusses the simulation results and provides recommendations for improving thermal comfort in energy efficient homes. 


\section{Problem Definition}

The development of air distribution systems for very low load homes is an integral part of residential system research and development in systems integration. As American homes begin to reach high energy savings levels, space conditioning systems will be downsized to the point where the air flow volumes required to meet the small remaining heating and cooling loads may be too small to maintain uniform room air mixing. Most important are concerns about thermal comfort, which can be affected by poor distribution of conditioned air at reduced design flow rates.

American Society of Heating, Refrigeration and Air-Conditioning Engineers (ASHRAE 2009, 2010) and Air Conditioning Contractors of America (ACCA Manual T 1992, ACCA Manual D 1995) provide overall design guidance documents for conventional homes; however, these have limitations and discrepancies. Room air distribution design guidelines need to be developed to address these. The guidelines should also be appropriate for heating and cooling operation in high performance homes. Good air mixing for heating/cooling is not guaranteed for a system that might work well in both cooling and heating modes, particularly under part-load conditions.

Well-designed high sidewall inlet jets are one of the simplest and most promising approaches for delivering conditioned air in high-performance homes because they are not blocked by furniture and can provide uniform air mixing of the conditioned air within the space. The system of interest incorporates a high sidewall supply air inlet and a low return air directly below. Potential poor air mixing is possible with this type of air distribution particularly in heating mode. Because of the reduced design flow rate of HVAC systems, stratification may form in energy efficient homes.

\section{Approach}

We used computational fluid dynamics modeling to evaluate the performance of high sidewall air supply inlets in heating and cooling seasons. We simulated three air inlet sizes: 8 -in. $(0.2 \mathrm{~m})$ $\times 1$-in. $(0.025 \mathrm{~m}), 8$-in. $(0.2 \mathrm{~m}) \times 4$-in. $(0.1 \mathrm{~m})$ and 10 -in. $(0.25 \mathrm{~m}) \times 6$-in. $(0.15 \mathrm{~m})$. For each inlet, we varied the supply velocity and supply temperature and controlled the supply via a thermostat set at $71^{\circ} \mathrm{F}(294.81 \mathrm{~K})$. Simulations ended when 1 air change was supplied to the room and the performance of the three inlets was then compared for heating and cooling modes.

At the end of each simulation, thermal comfort is evaluated by determining the Air Diffusion Performance Index (ADPI). ADPI is defined in the occupied zone and is a thermal comfort criterion based on the air velocity and temperature distributions obtained from the numerical simulation output. The definition of the occupied zone and the criteria used in calculating ADPI are discussed in more details in Conditioning Jet Performance Metrics section. The thermal loads studied were applied as heat gain/loss through the exterior wall and ceiling and were considered to mimic peak load conditions. A wide range of system capacities was considered by varying the supply jet velocity and temperature. 


\section{Methodology}

The finite volume method (software FLUENT 6.3, 2006) was used to model simple and representative room and inlet geometries, air supply flow rates, and temperatures. Details on the boundary conditions used are provided in the following section.

The model addressed peak loads that are representative of perimeter zones high-performance homes. Load densities of $14.6 \mathrm{Btu} / \mathrm{h} \cdot \mathrm{ft}^{2}\left(46.02 \mathrm{~W} / \mathrm{m}^{2}\right)$ for heating and $10 \mathrm{Btu} / \mathrm{h} \cdot \mathrm{ft}^{2}\left(31.52 \mathrm{~W} / \mathrm{m}^{2}\right)$ for cooling were applied. Load density is defined as the room thermal load divided by the room floor area. As a reference point, a Chicago house in January has a heating peak load density of about $14.5 \mathrm{Btu} / \mathrm{h} \cdot \mathrm{ft}^{2}\left(45.7 \mathrm{~W} / \mathrm{m}^{2}\right)$. For cooling in July, the same house in Phoenix has a cooling peak load density of about $11.2 \mathrm{Btu} / \mathrm{h} \cdot \mathrm{ft}^{2}\left(35.3 \mathrm{~W} / \mathrm{m}^{2}\right)$. These loads were calculated using BEoptE+ 1.1 (Christensen et al., 2006). Table A lists the thermal characteristics of the reference house, which are found in high performance homes. These densities were multiplied by the floor area and the outcome was distributed between the ceiling and at the exterior wall opposite to the air jet. The proportional thermal load distribution between the ceiling and the wall was based on their respective R-values. The room load density, $\ddot{q}_{l d}$, was used to determine the total rate of heat transfer into the room, $q_{t}$ as

where

$$
\begin{aligned}
& q_{t}=\ddot{q}_{l d} \cdot A_{f}=A_{w} \cdot \ddot{q}_{w}+A_{c} \cdot \ddot{q}_{c} \\
& \frac{\ddot{q}_{w}}{\ddot{q}_{c}}=\frac{R_{c}}{R_{w}}
\end{aligned}
$$

$A_{f}, A_{w}, A_{c}=$ are respectively the room floor area, exterior wall area, and ceiling area $\left[\mathrm{ft}^{2}\right]$

$\ddot{q}_{w} \quad=$ exterior wall heat flux $\left[\mathrm{Btu} / \mathrm{h} \cdot \mathrm{ft}^{2}\right]$

$\ddot{q}_{c} \quad=$ ceiling heat flux $\left[\mathrm{Btu} / \mathrm{h} \cdot \mathrm{ft}^{2}\right]$

$R_{w} \quad=$ exterior wall R-value $\left[\mathrm{ft}^{2} \cdot \mathrm{h}^{\circ} \mathrm{F} / \mathrm{Btu}\right]$

$R_{C} \quad=$ ceiling R-value $\left[\mathrm{ft}^{2} \cdot \mathrm{h} \cdot{ }^{\circ} \mathrm{F} / \mathrm{Btu}\right]$

\begin{tabular}{|c|c|c|c|}
\hline Floor area $\left(\mathrm{ft}^{2}\right)$ & 2500 & Window SHGC & 0.425 \\
\hline Framing & $2 \times 6$ & Window area $(\%)$ & $18 \%$ \\
\hline Ceiling $\mathrm{R}\left(\mathrm{ft}^{2} \cdot \mathrm{h} \cdot{ }^{\circ} \mathrm{F} / \mathrm{Btu}\right)$ & 30.8 & Infiltration & 7.5ACH@50Pa \\
\hline Wall R $\left(\mathrm{ft}^{2} \cdot \mathrm{h} \cdot{ }^{\circ} \mathrm{F} / \mathrm{Btu}\right)$ & 23.1 & Heating set point & $71^{\circ} \mathrm{F}$ \\
\hline Window U $\left(\mathrm{BTU} / \mathrm{h} \cdot{ }^{\circ} \mathrm{F} \cdot \mathrm{ft}^{2}\right)$ & 0.325 & Cooling set point & $76^{\circ} \mathrm{F}$ \\
\hline
\end{tabular}

Table A. Reference house construction type and assumptions used to calculate loads.

In reality, loads are not always uniform over the wall area and may be concentrated on parts of the wall such as on the window area. These situations are not considered in this study and represent one of the limitations of the current study. A 4 in. $(0.1 \mathrm{~m}) \times 4$ in. $(0.1 \mathrm{~m})$ thermostat with a set-point of $71^{\circ} \pm 1^{\circ} \mathrm{F}(294.81 \pm 0.56 \mathrm{~K})$ was built into the model to control the room temperature. The thermostat was mounted on the wall parallel to the inlet air jet at $4 \mathrm{ft}(1.22 \mathrm{~m})$ from the floor (see Figure 1). 
The current three-dimensional model provides detailed velocity and temperature distributions that can be used to evaluate room air mixing and thermal comfort. Although, this model has some limitations and does not take into account:

- The non uniformity in thermal loads applied to the room, which can be caused by windows, wood studs, etc

- Transient conduction through the walls. The current model assumes massless walls with constant and uniform loads applied at the inner surfaces of walls and ceiling

- Solar load variability

- Effect of return location

- Individual indoor heat generation sources

- Effect of furniture

It is expected that the simplified approach followed will answer the fundamental stability questions that dominate the air mixing process. The primary goal of this study is to identify operating parameters that ensure robust mixing and design space conditioning systems for high performance homes to avoid operating parameters that will result in poor air mixing.

\section{Model Setup}

Room dimensions reflected typical residential designs and had a 9-ft (2.74 m) ceiling, $11 \mathrm{ft}(3.35$ $\mathrm{m})$ width, transverse to the inlet jet throw, and $12 \mathrm{ft}(3.66 \mathrm{~m})$ length. Room length is in the direction of the jet throw. All inlets were modeled as open jets with air discharged in a uniform profile normal to the inlet face. No attempt was made to include non-uniform velocity profiles from actual diffusers mounted downstream of elbows, but they could be part of future simulations.

Three inlets in 8-in. $(0.2 \mathrm{~m}) \times 1$-in. $(0.025 \mathrm{~m}), 8$-in. $(0.2 \mathrm{~m}) \times 4$-in. $(0.1 \mathrm{~m})$ and 10 -in. $(0.25 \mathrm{~m}) \times$ 6 -in. $(0.15 \mathrm{~m})$ sizes were evaluated. Inlets were mounted with the upper edge of the opening 9 in. $(0.23 \mathrm{~m})$ from the ceiling and were modeled as uniform velocity boundaries. Actual velocity profiles at the inlet are likely to be non-uniform due to the effects of upstream ductwork. However, it is expected that the simplified approach used will accurately predict the airflow characteristics used to evaluate thermal comfort, which is the main objective of this study.

The return outlet was located directly below the supply inlet, with the lower edge of the opening 4 in. $(0.1 \mathrm{~m})$ from the floor. The outlet area was much larger than any of the inlets, to have a low air speed approaching the opening. The outlet was modeled as a completely open pressure boundary, set to 0 psig $(0 \mathrm{~Pa})$.

Supply velocities varied from $197 \mathrm{fpm}(1 \mathrm{~m} / \mathrm{s})$ to $2146 \mathrm{fpm}(10.8 \mathrm{~m} / \mathrm{s})$, corresponding airflow rates in the range of $11 \mathrm{cfm}\left(0.005 \mathrm{~m}^{3} / \mathrm{s}\right)$ to $300 \mathrm{cfm}(0.142)$, depending on inlet size. For heating cases, the supply temperature ranged from $95^{\circ}$ to $120^{\circ} \mathrm{F}(308$ to $322 \mathrm{~K})$; the initial room temperature was fixed at $65^{\circ} \mathrm{F}(291 \mathrm{~K})$. In cooling, the supply air temperature varied from $55^{\circ} \mathrm{F}$ $(286 \mathrm{~K})$ to $65^{\circ} \mathrm{F}(292 \mathrm{~K})$ and the initial room temperature was fixed at $80^{\circ} \mathrm{F}(300 \mathrm{~K})$. 
Wall characteristics, gridding, and other solution parameters were chosen to ensure convergence. Since the inlets are placed in the middle of a wall, there is a plane of transverse symmetry. This assumption enabled the simulations to model only one-half of the room, thus halving computational expense. The computational grid was made up of hexahedral cells with high grid density near the walls and in the vicinity of the supply inlets and return outlets. The ReNormalization Group (RNG) k- $\varepsilon$ model was used for turbulence and y+ values were checked early on to make sure they were in the correct range to allow standard wall functions to be used. Incompressible ideal gas law was used for density calculations. The transient simulations were initially run with small time steps, with gradual increases in time step size as the solution progressed. Simulations were performed on a multiprocessor workstation with four processors. Depending on domain size, the time necessary to complete 1 air change, and other variables, simulations could take up to six days to complete.

Figure 1 shows the geometry outline of the computational domain. Room walls were considered to be massless and thermal loads were applied at the inner surfaces of ceiling and outside wall. The floor and the remaining walls of the room were defined to be adiabatic. The domain is shown with the plane of symmetry bisecting the room, through the supply inlet and return outlet.

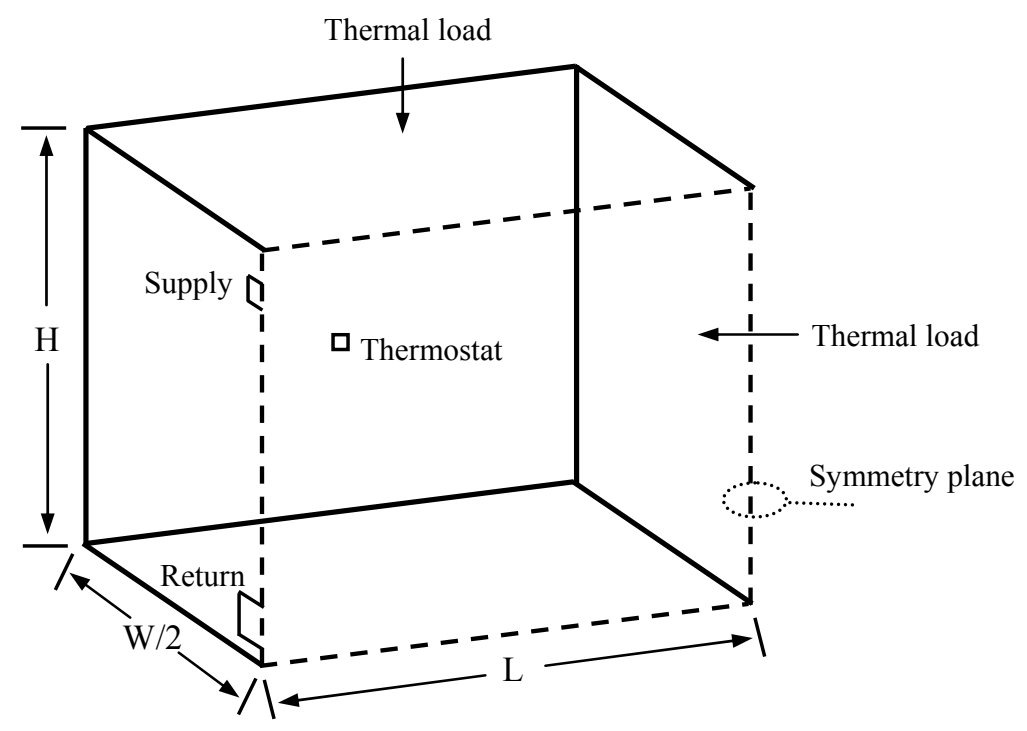

Figure 1. Sketch of the computational domain (not to scale) showing the locations of supply, return, and thermostat in the room. Thermal loads are applied only to the ceiling and to the right wall to approximate load distributions in a perimeter zone.

The air handler is an essential component of forced air heating and air-conditioning systems and should not be ignored in the discussion of room air distribution. To evaluate the potential energy impacts of different mixing strategies, we calculated the fan power required to deliver the desired supply flow rates to the room. We assumed a fan with a total pressure rise of $0.044 \mathrm{Psig}(300 \mathrm{~Pa}$ ) and a fan power ratio of $0.364 \mathrm{~W} / \mathrm{cfm}$ as specified in the Building America House Simulation Protocols (Hendron and Engebrecht, 2010). 


\section{Conditioning Jet Performance Metrics}

Performance was characterized by a number of dimensionless groups. The isothermal throw of the inlet jet is defined as

$$
X \equiv \frac{K^{\prime} Q}{V_{x} \sqrt{A_{o}}}
$$

Where

$X[\mathrm{ft}]=$ the Zone 3 throw of the jet to the point where the centerline velocity decays to the value of $V_{x}, 50 \mathrm{fpm}(0.25 \mathrm{~m} / \mathrm{s})$

$K^{\prime} \quad=$ a proportionality constant of value 5.7

$Q \quad=$ the flow rate from the supply inlet $[\mathrm{cfm}]$; and $A_{o}$ is the area of the inlet, $\left[\mathrm{ft}^{2}\right]$

The isothermal throw is compared to the length of the room in the throw ratio:

$$
N_{T} \equiv \frac{X}{L}
$$

where

$L=$ room dimension in the direction of the throw $[\mathrm{ft}]$

The air diffusion performance index (ADPI) was calculated at the end of the simulation when 1 air change was supplied to the room. ADPI is defined in a zone between 4 in. $(0.1 \mathrm{~m})$ and $72 \mathrm{in}$. $(1.83 \mathrm{~m})$ from the floor, $2 \mathrm{ft}(0.61 \mathrm{~m})$ from exterior walls, and $1 \mathrm{ft}(0.3 \mathrm{~m})$ from interior walls (ASHRAE Standard 55, 2010). ADPI is a simple comfort criterion based on local temperature, average temperature in the whole room, and local air speed. ADPI was chosen as the performance metric because of its simplicity. It does not involve determination of mean radiant temperature, amount of clothing, or activity level, all of which were beyond the scope of this study and subject to highly variable conditions such as window placement. ADPI uses effective draft temperature

$$
\theta \equiv\left(T-T_{\text {set }}\right)-0.07\left(V_{x}-30\right)
$$

where

$T=$ the local air temperature $\left[{ }^{\circ} \mathrm{F}\right]$

$T_{\text {set }} \quad=$ the thermostat set point $\left[{ }^{\circ} \mathrm{F}\right]$

$V_{x} \quad=$ the local air speed [fpm]

Effective draft temperature must be $-3^{\circ}(-1.7)$ to $2^{\circ} \mathrm{F}(1.1 \mathrm{~K})$ and local air speed below $70 \mathrm{fpm}$ $(0.35 \mathrm{~m} / \mathrm{s})$ for maximum comfort (ASHRAE 2009). In the zone of interest, effective draft temperature and air speed were determined for each cell. The number of cells meeting these requirements was compared to the total number of cells to determine the ADPI for the simulation. The room has an acceptable ADPI level when its value is greater than 0.7. System operation with ADPI below 0.7 is not recommended. 


\section{Results and Discussion}

This section is divided into two subsections to address heating and cooling conditions. The first subsection presents the outcomes of the heating study showing the effects of thermal loads, thermostat control, and inlet size on the thermal comfort. Results in cooling mode are covered in the second subsection. Each combination of inlet velocity and temperature defines the peak thermal load for the room. These loads define HVAC system capacity and were supplied to meet the peak heat loss/gain through the building envelope. In this study we did not model separate indoor heat generation sources and applied the entire peak load at the ceiling and exterior wall of the room. In order to investigate the effect of operating conditions on ADPI, we explored a wide range of system capacities including undersized and oversized systems. Three sizes of air inlet were evaluated for each mode (heating and cooling).

\section{Heating Mode}

This section presents the results in heating mode with a peak load density of $14.6 \mathrm{Btu} / \mathrm{h} \cdot \mathrm{ft}^{2}(46.02$ $\left.\mathrm{W} / \mathrm{m}^{2}\right)$. The analysis considered three different supply inlet sizes: an 8-in. $(0.2 \mathrm{~m}) \times 1$-in. $(0.025$ $\mathrm{m})$, an 8 -in. $(0.2 \mathrm{~m}) \times 4$-in. $(0.1 \mathrm{~m})$ and a 10 -in. $(0.25 \mathrm{~m}) \times 6$-in. $(0.15 \mathrm{~m})$. All simulations shared uniform room temperature of $65^{\circ} \mathrm{F}(291.5 \mathrm{~K})$ as an initial condition. The thermostat set-point was set at $71^{\circ}(294.82) \pm 1^{\circ} \mathrm{F}(0.56 \mathrm{~K})$. The results will be presented first for the smallest then for intermediate and large inlet sizes.

The performance of the smaller inlet $(8 \times 1)$ is evaluated in Figure 2, which shows the variations of air temperature near the thermostat and the supply velocity as a function of time for two supply velocities of $558 \mathrm{fpm}(2.83 \mathrm{~m} / \mathrm{s})$ and $714 \mathrm{fpm}(3.63 \mathrm{~m} / \mathrm{s})$. At this supply temperature of $120^{\circ} \mathrm{F}(322 \mathrm{~K})$, we see two system capacities corresponding to a $15 \%$ undersized system running continuously (558 fpm) and a 9\% oversized system characterized by cycling (714 fpm). Low values of ADPI were found for these conditions: 0.16 for $\mathrm{V}_{\mathrm{S}}=558 \mathrm{fpm}(2.83 \mathrm{~m} / \mathrm{s})$ and 0.24 for $\mathrm{V}_{\mathrm{S}}=714 \mathrm{fpm}(3.62 \mathrm{~m} / \mathrm{s})$.

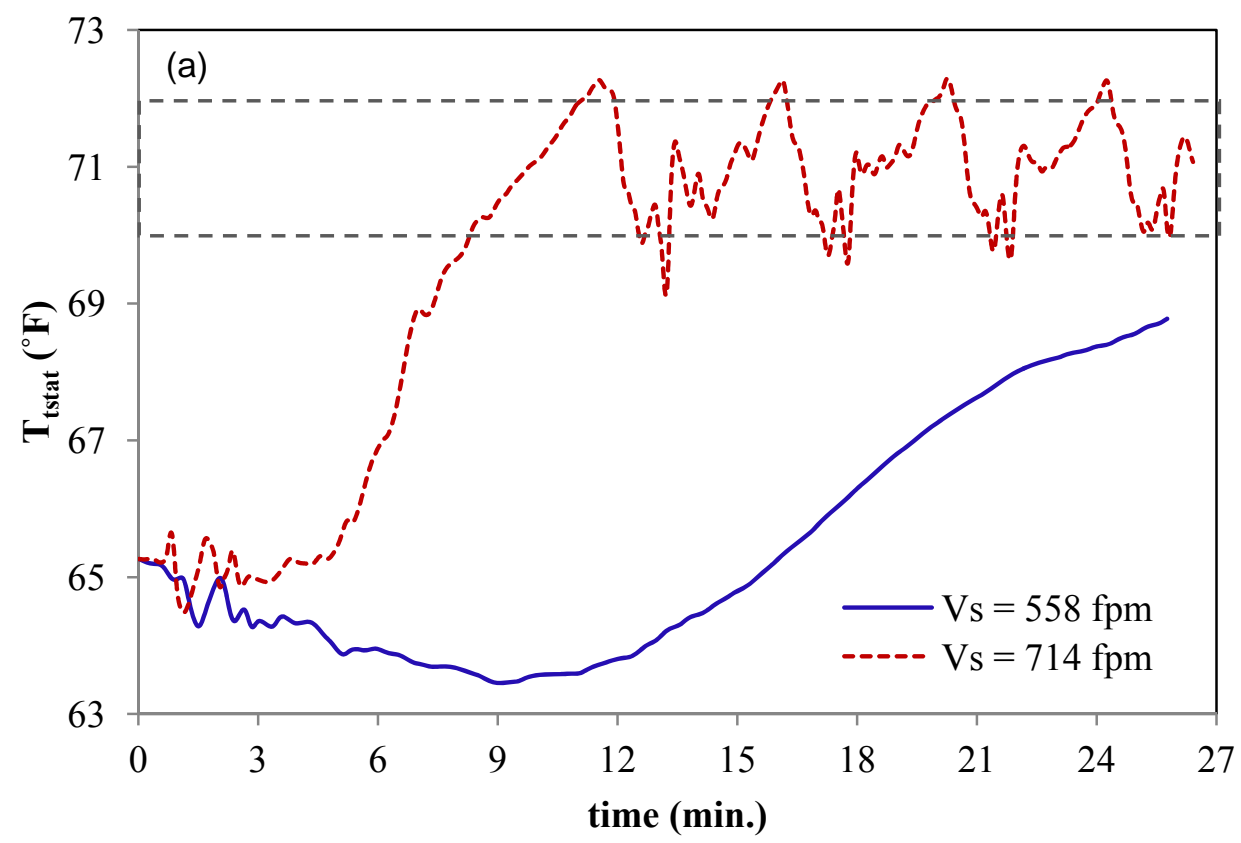




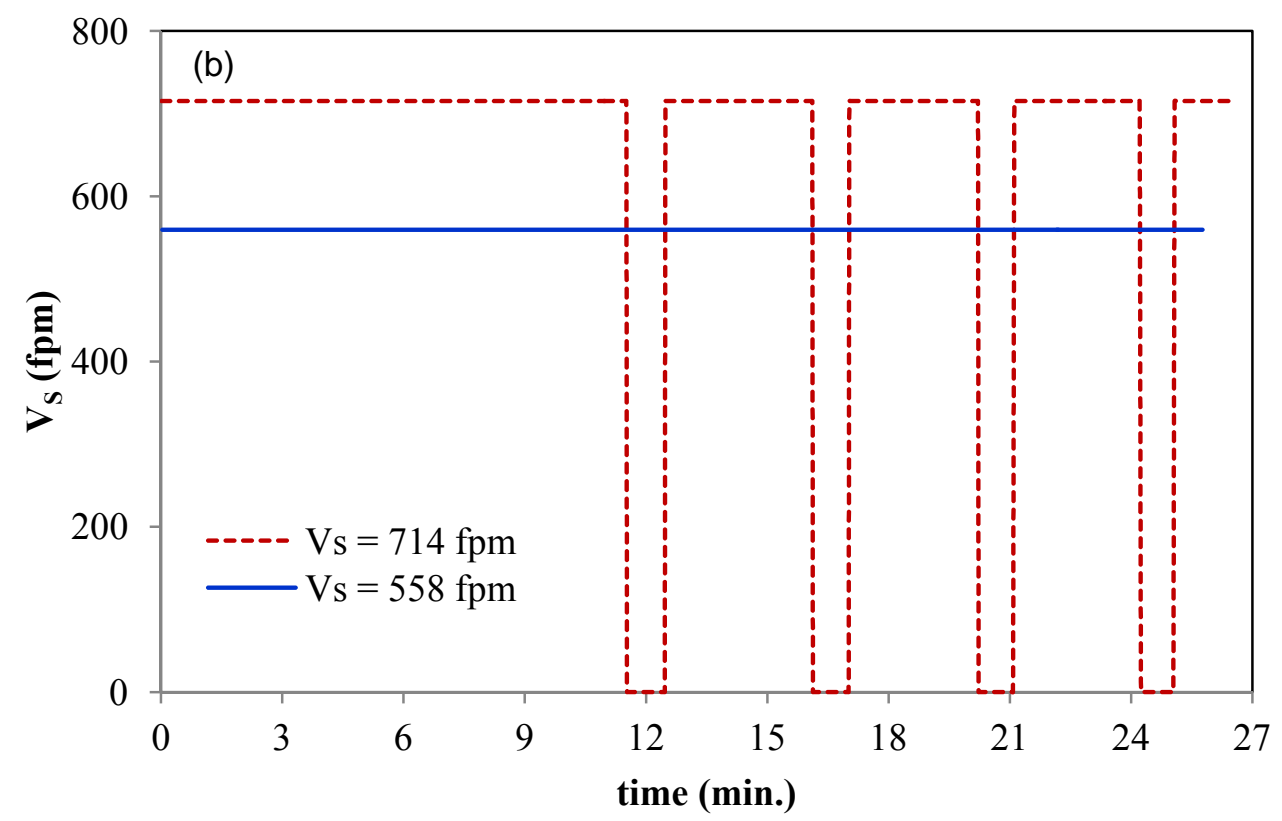

Figure 2. Time history of air temperature near the thermostat (a) and velocity at the inlet (b) from an $8 \times 1$ inlet when supplied by $\mathrm{T}_{\mathrm{s}}$ of $120^{\circ} \mathrm{F}(322 \mathrm{~K})$

Figure 3 illustrates the time history of air temperature near the thermostat and the corresponding supply velocity for the intermediate sized $(8 \times 4)$ inlet. For a fixed supply velocity, the system capacity is increased by a factor of four when the inlet size is increased from $8 \times 1$ to $8 \times 4$. To observe the effect of the supply velocity on the results, the data was plotted for two supply velocities of $558 \mathrm{fpm}(2.83 \mathrm{~m} / \mathrm{s})$ and $714 \mathrm{fpm}(3.62 \mathrm{~m} / \mathrm{s})$. The air temperature increased quickly at high supply velocity of $714 \mathrm{fpm}(3.62 \mathrm{~m} / \mathrm{s})$ and passed the thermostat set-point within $2 \mathrm{~min}$ of operation. The temperature continued to increase even when the supply air was off and reached a maximum, which was about $4^{\circ} \mathrm{F}(2.22 \mathrm{~K})$ above the thermostat set point. This was caused by the high supply velocity that led to a significant circulation of hot air in the room. The short cycling indicates that the system capacity is larger than the peak load. At 1 air change, the supply velocity of $558 \mathrm{fpm}(2.83 \mathrm{~m} / \mathrm{s})$ had an ADPI of 0.26 while $714 \mathrm{fpm}(3.62 \mathrm{~m} / \mathrm{s})$ provided slightly higher value of 0.36 . 

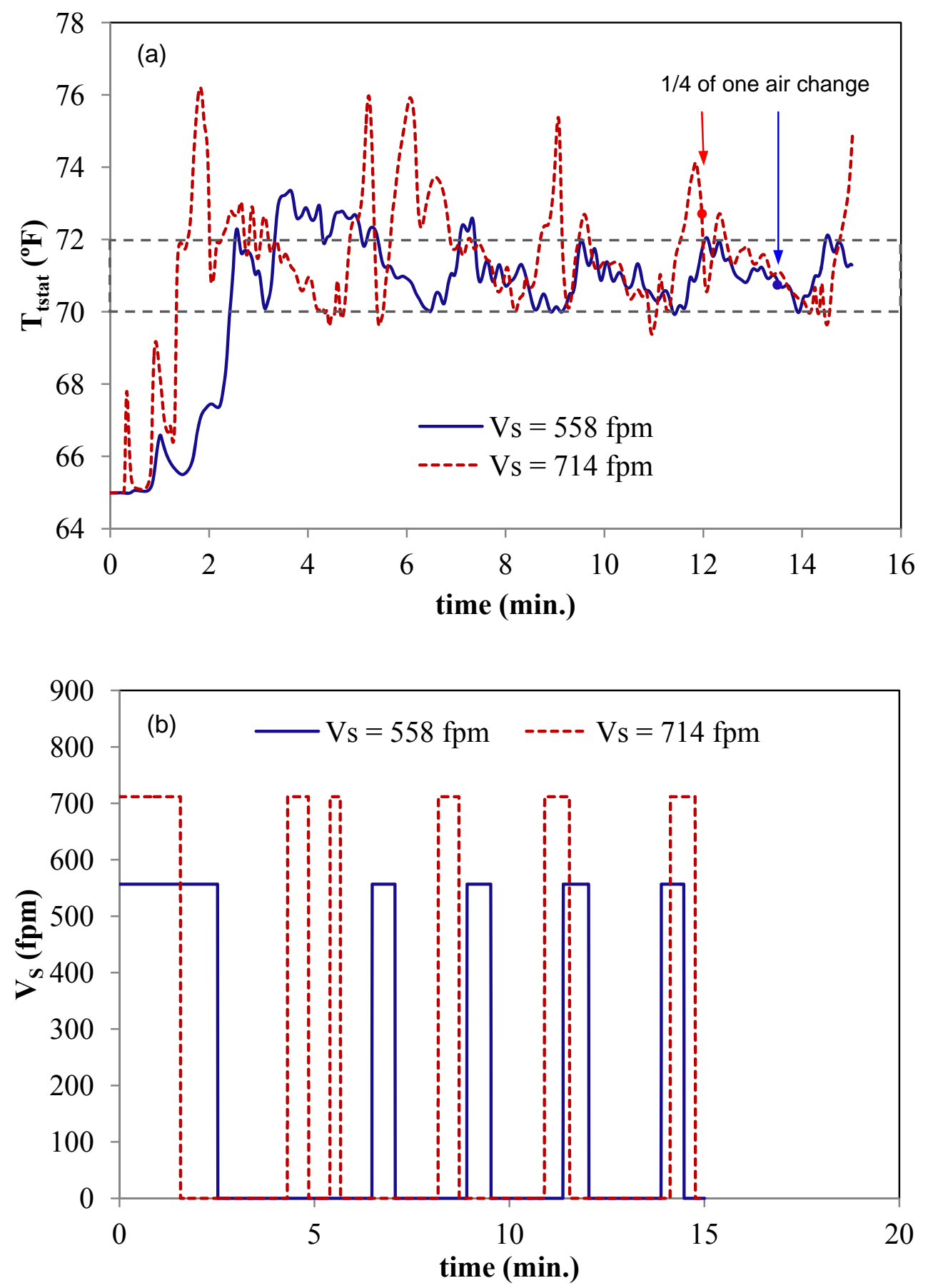

Figure 3. Air temperature near the thermostat (a) and velocity at the inlet from an $8 \times 4$ inlet (b) as a function of time when supplied by $\mathrm{T}_{\mathrm{s}}$ of $120^{\circ} \mathrm{F}(322 \mathrm{~K})$

The temperature distribution at the symmetry plane of the room with an $8 \times 4$ supply inlet is plotted in Figure 4 for two supply velocities of $558 \mathrm{fpm}(2.83 \mathrm{~m} / \mathrm{s})$ and $714 \mathrm{fpm}(3.62 \mathrm{~m} / \mathrm{s})$, both at $120^{\circ} \mathrm{F}(322 \mathrm{~K})$. Temperature distributions were plotted after 1 air change. Poor mixing was observed at $\mathrm{V}_{\mathrm{S}}$ of $558 \mathrm{fpm}(2.83 \mathrm{~m} / \mathrm{s})$, which was limited to the upper half of the room. The 
lower half was highly stratified. As the supply velocity was increased to $714 \mathrm{fpm}(3.62 \mathrm{~m} / \mathrm{s})$, better mixing was achieved, but it was not enough to eliminate the stratification in the lower regions of the room.

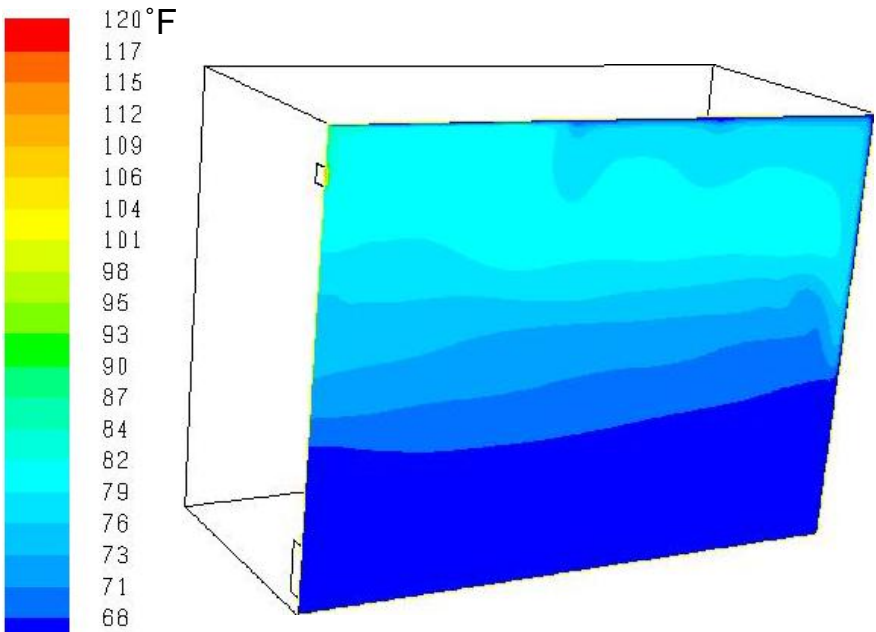

(a)

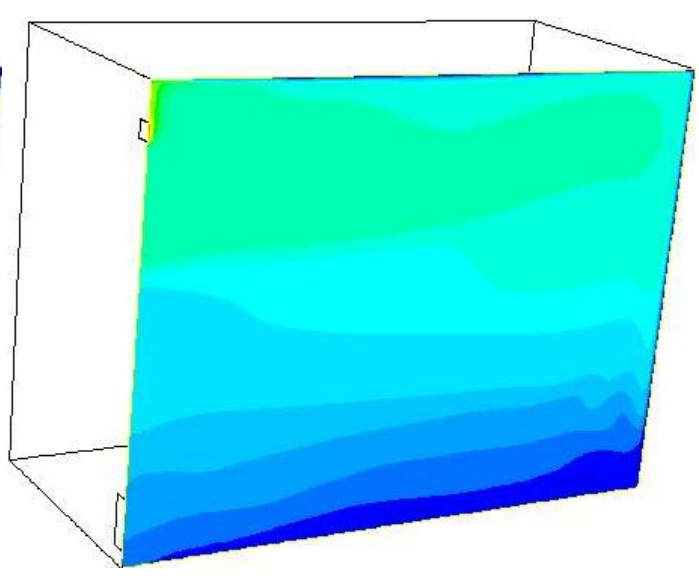

(b)

Figure 4. Temperature distribution at the symmetry plane of the room with an $8 \times 4$ inlet when supplied by $T_{s}$ of $120^{\circ} \mathrm{F}(322 \mathrm{~K})$ : (a) $\mathrm{V}_{\mathrm{s}}=558 \mathrm{fpm}(2.83 \mathrm{~m} / \mathrm{s})$ and (b) $\mathrm{V}_{\mathrm{s}}=714 \mathrm{fpm}(3.62 \mathrm{~m} / \mathrm{s})$

To observe the effect of the supply air temperature on the heating cycles, we presented the time history of air temperature near the thermostat and the velocity at the inlet for $V_{\mathrm{S}}$ of $558 \mathrm{fpm}(2.83$ $\mathrm{m} / \mathrm{s}$ ) for two supply air temperatures of $95^{\circ}(308.15)$ and $120^{\circ} \mathrm{F}(322 \mathrm{~K})$ (see Figure 5). Both curves presented similar behavior in the first $2 \mathrm{~min}$ of operation. They started at the initial temperature of $65^{\circ} \mathrm{F}(291.5 \mathrm{~K})$ and increased toward the thermostat set-point before entering a quasi-steady state regime. In this regime the curve associated with the higher supply temperature of $120^{\circ} \mathrm{F}(322 \mathrm{~K})$ oscillated within the deadband between $70^{\circ}(294.3 \mathrm{~K})$ to $72^{\circ} \mathrm{F}(295.4 \mathrm{~K})$; the curve related to $95^{\circ} \mathrm{F}(308.15 \mathrm{~K})$ presented higher oscillation amplitudes. 

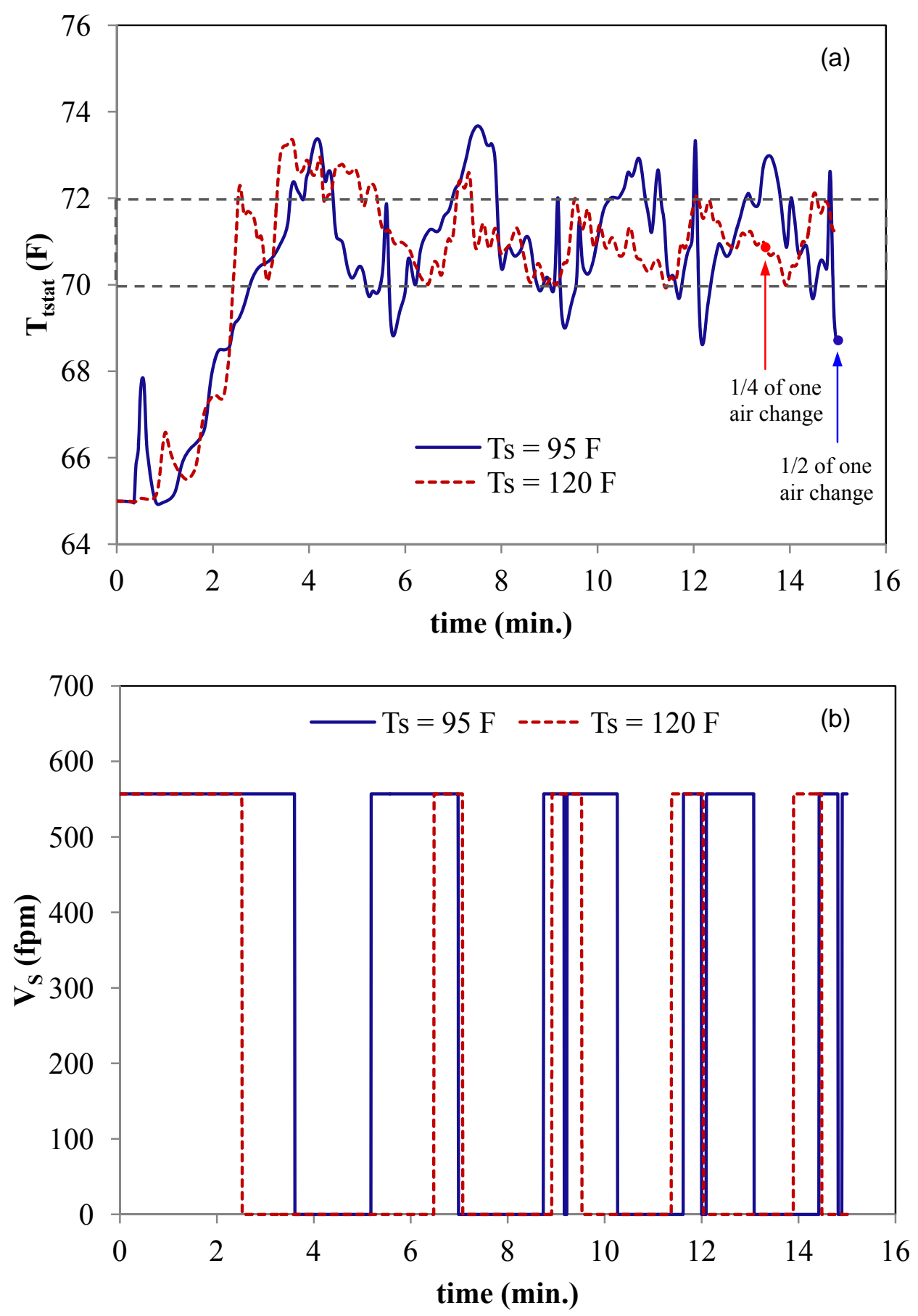

Figure 5. Temporal evolution of air temperature near the thermostat (a) and supply velocity at the inlet (b) of the room with $8 \times 4$ inlet when supplied by two different temperatures, $95^{\circ} \mathrm{F}(308 \mathrm{~K})$ and $120^{\circ} \mathrm{F}(322 \mathrm{~K})$ with $\mathrm{V}_{\mathrm{s}}=558 \mathrm{fpm}(2.83 \mathrm{~m} / \mathrm{s})$

Isotherm plots in the room, supplied by $95^{\circ} \mathrm{F}(308 \mathrm{~K})$ air, are depicted in Figure 6 . Three supply velocities were considered corresponding to a low, intermediate, and high operation of the system. For a better visualization, the results were plotted at the symmetry plane (left) and at different cross sections in the direction of the air jet throw (right) when 1 air change was 
supplied to the room. At low velocity of $214 \mathrm{fpm}(1.1 \mathrm{~m} / \mathrm{s})$, the room was highly stratified and the jet had no momentum to penetrate into the lower half of the room. The mixing quality increased with the supply velocity and good mixing was observed at $\mathrm{V}_{\mathrm{S}}$ of $714 \mathrm{fpm}(3.62 \mathrm{~m} / \mathrm{s})$. For a given supply velocity, the supply temperature of $95^{\circ} \mathrm{F}(308 \mathrm{~K})$ provided a better mixing than $120^{\circ} \mathrm{F}(322 \mathrm{~K})$.

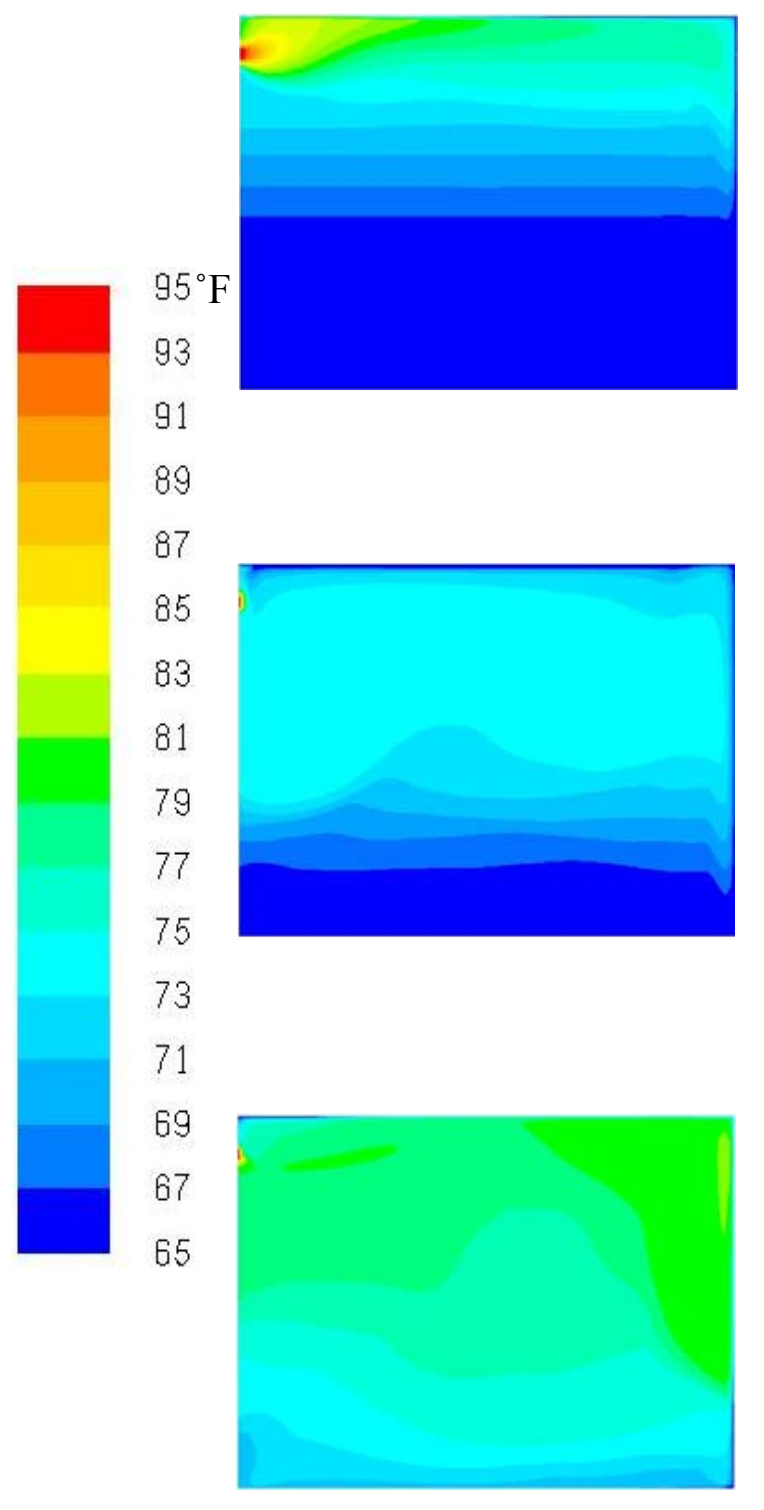

(a)

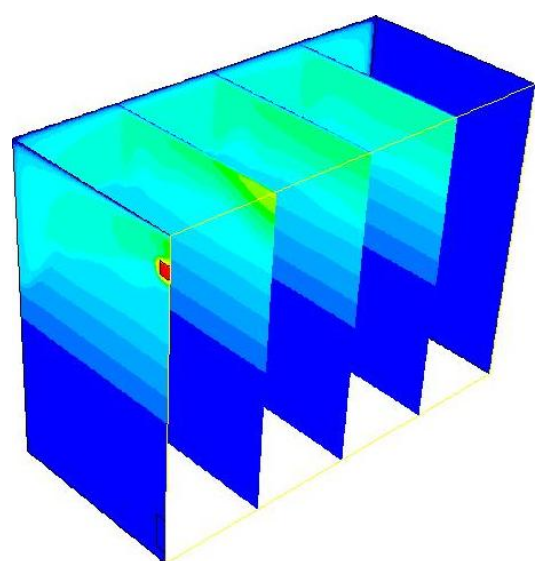

(b)

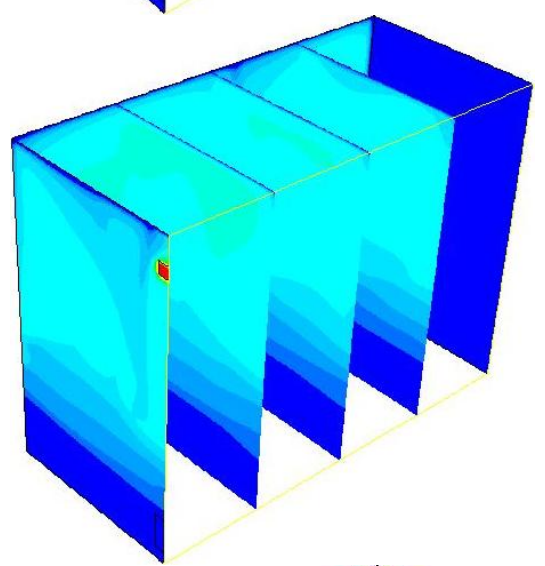

(c)

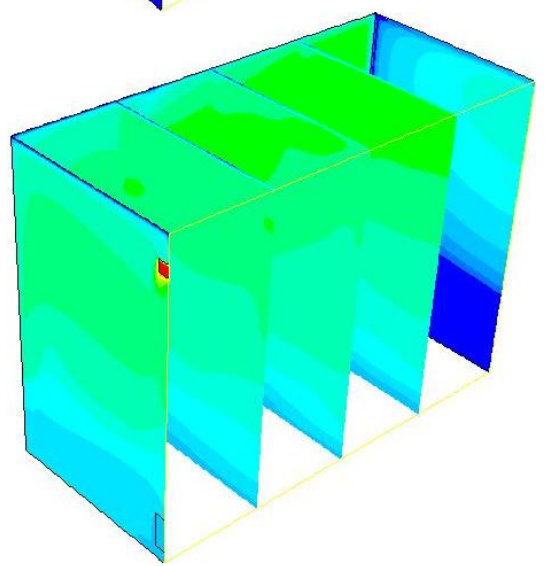

Figure 6. Temperature distribution in the room, with an $8 \times 4$ supply inlet, at 1 air change when supplied by $T_{s}$ of $95 \mathrm{~F}(308 \mathrm{~K})$ : (a) $\mathrm{V}_{\mathrm{s}}=214 \mathrm{fpm}(1.1 \mathrm{~m} / \mathrm{s})$, (b) $\mathrm{V}_{\mathrm{s}}=558 \mathrm{fpm}(2.83 \mathrm{~m} / \mathrm{s})$, and (c) $\mathrm{V}_{\mathrm{s}}=$ $714 \mathrm{fpm}(3.62 \mathrm{~m} / \mathrm{s})$. Left plots are at the symmetry plane and right plots are at different cross sections throughout the room. 
To quantify the comfort levels associated with the situations presented in Figure 6, the corresponding draft temperature is plotted in Figure 7. The ADPI was evaluated at 1 air change by comparing the cells with acceptable draft temperature and air speed against the total cells in the occupied zone. The limits on the height of the occupied zone are marked by a red line on the bottom row. As expected, regions of acceptable draft temperature (bottom row) are very limited at low and intermediate velocities of $214 \mathrm{fpm}(1.1 \mathrm{~m} / \mathrm{s})$ and $558 \mathrm{fpm}(2.83 \mathrm{~m} / \mathrm{s})$ and continued to increase with the supply velocity. As a result, better ADPI level was observed at $V_{S}$ of $714 \mathrm{fpm}$ $(3.62 \mathrm{~m} / \mathrm{s})$ with an average ADPI of 0.76 , which is slightly above the acceptable value of 0.7 .

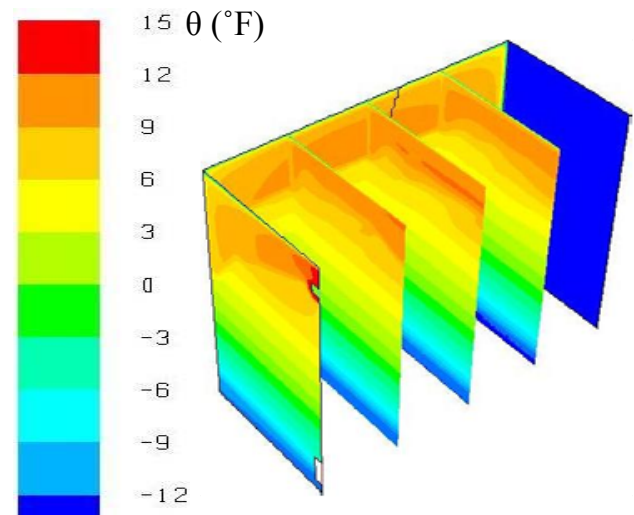

(a)

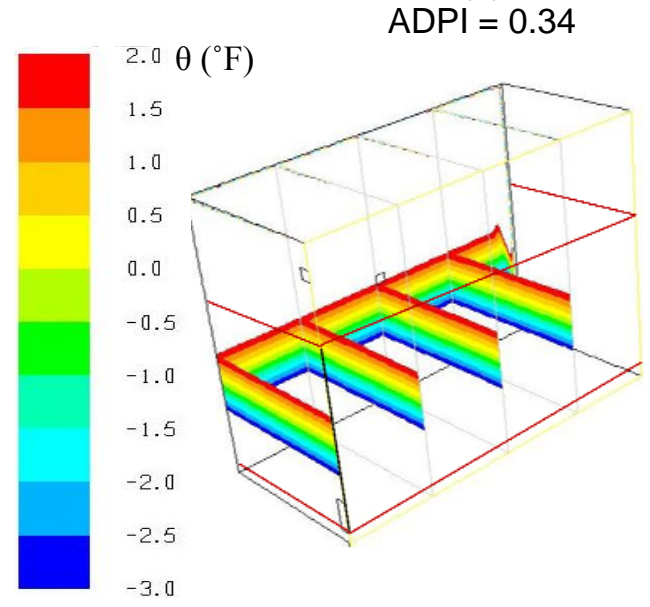

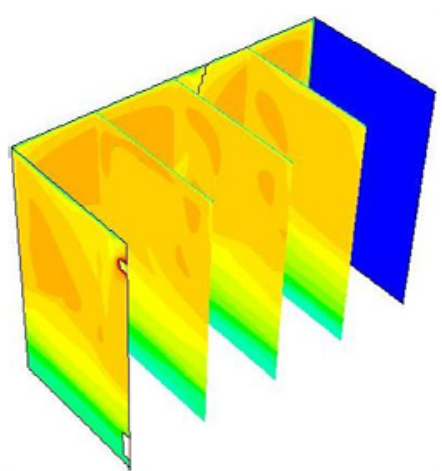

(b)

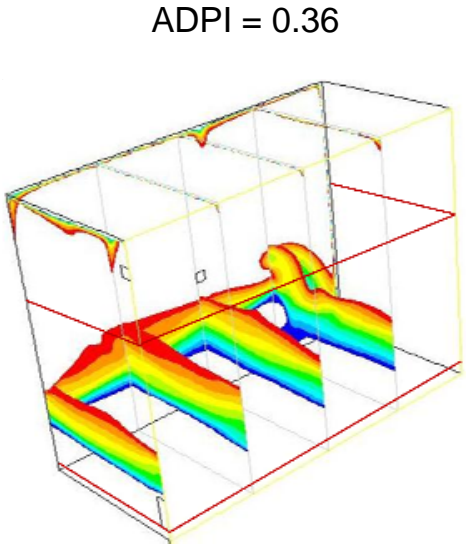

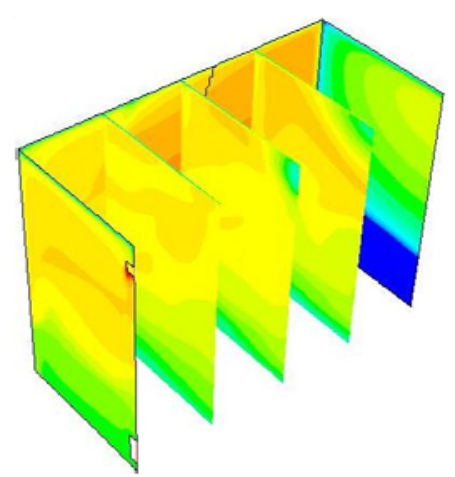

(c)

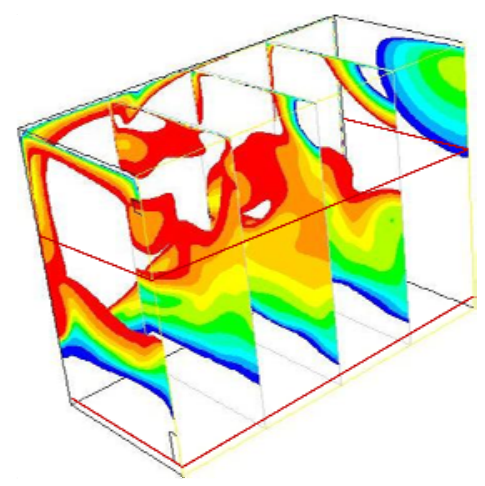

Figure 7. Distribution of draft temperature in the room, with an $8 \times 4$ inlet, when $T_{S}=95^{\circ} \mathrm{F}(308 \mathrm{~K})$ :

(a) $V_{s}=214 \mathrm{fpm}(1.1 \mathrm{~m} / \mathrm{s})$, (b) $V_{s}=558 \mathrm{fpm}(2.83 \mathrm{~m} / \mathrm{s})$, and (c) $V_{s}=714 \mathrm{fpm}(3.62 \mathrm{~m} / \mathrm{s})$. Top row shows the draft temperature at full scale and the bottom row shows acceptable draft temperature, between -3 and $2^{\circ} \mathrm{F}$.

The simulation results with an $8 \times 4$ inlet showed that the mixing quality and comfort levels increased with the supply velocity and decreased with the supply temperature. The supply air at $95^{\circ} \mathrm{F}(308 \mathrm{~K})$ with a velocity of $714 \mathrm{fpm}(3.62 \mathrm{~m} / \mathrm{s})$ led to a good mixing and acceptable ADPI level (ADPI $=0.76)$. Further increase in supply velocity showed that ADPI goes through a maximum of 0.96 at a high velocity of $1430 \mathrm{fpm}(7.26 \mathrm{~m} / \mathrm{s})$ (see figure 19). 
It is expected that the $10 \times 6$ inlet will behave differently than the $8 \times 1$ and $8 \times 4$ as it is relatively larger. Figure 8 illustrates the temporal evolution of air temperature near the thermostat and the corresponding supply velocity in the room with a $10 \times 6$ inlet. This case is for $\mathrm{V}_{\mathrm{S}}=329 \mathrm{fpm}(1.67$ $\mathrm{m} / \mathrm{s})$ and $\mathrm{T}_{\mathrm{S}}=95^{\circ} \mathrm{F}(308 \mathrm{~K})$. Within 5 minutes of operation, both the temperature and the velocity entered a steady-state regime characterized by periodic ON/OFF cycles. The oscillation period is about $7 \mathrm{~min}$, which is shorter than actual operation cycles from a properly sized system. These operating conditions resulted is a $16 \%$ over sizing.

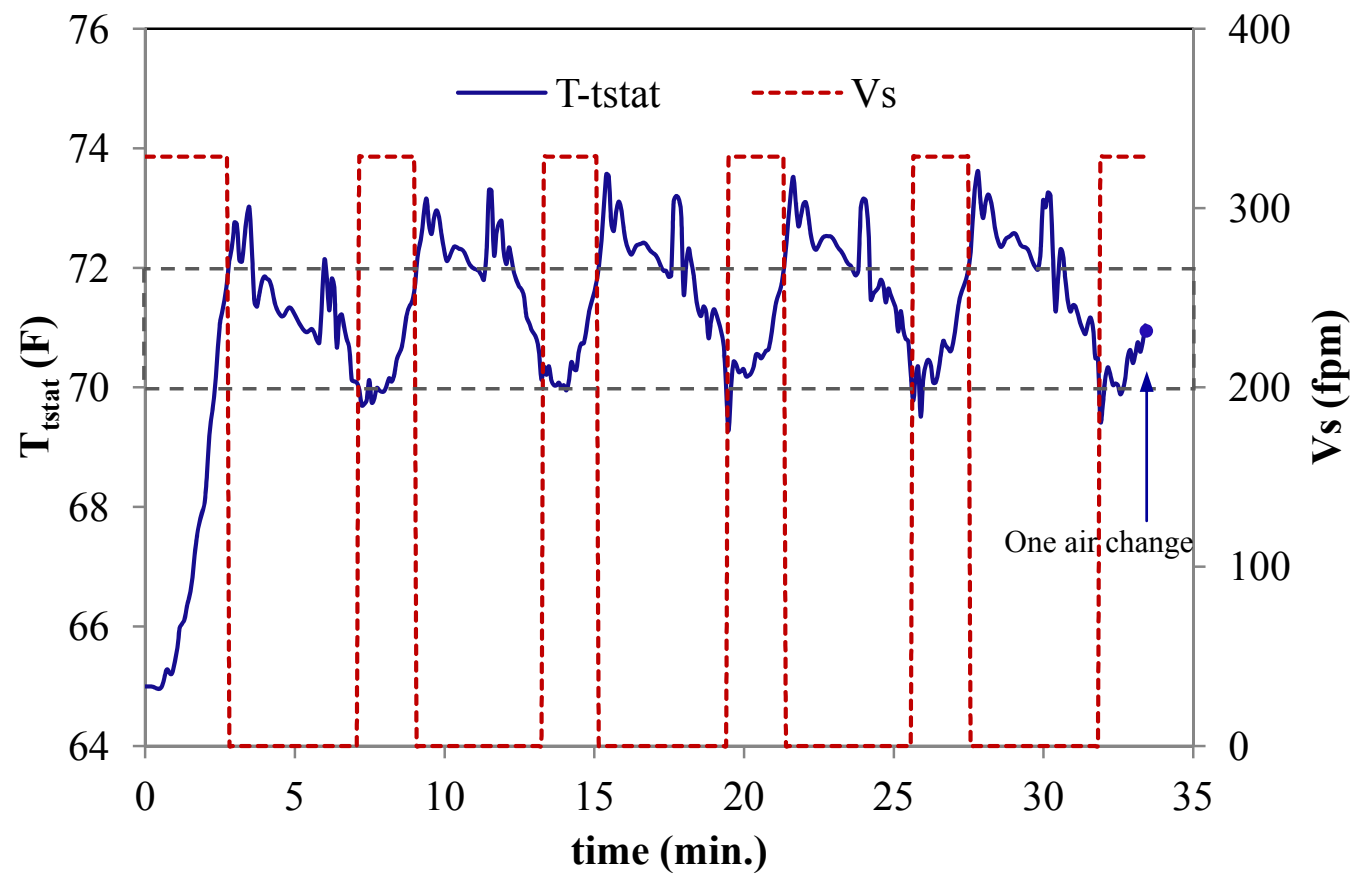

Figure 8. Temporal evolution of air temperature near the thermostat and the supply velocity at the $10 \times 6$ inlet when the room is supplied by $V_{s}=329 \mathrm{fpm}(1.67 \mathrm{~m} / \mathrm{s})$ and $T_{s}=95^{\circ} \mathrm{F}(308 \mathrm{~K})$

For a fixed supply velocity, the larger inlet with higher flow rates provided better mixing in heating mode compared to the smaller inlet. This was the case for all the supply velocities and temperatures tested. Figure 9 shows the temperature distribution at the symmetry plane (left) and at different cross sections (right) of the room with a $10 \times 6$ inlet. The plots are for two supply velocities of $329 \mathrm{fpm}(1.67 \mathrm{~m} / \mathrm{s})$ and $788 \mathrm{fpm}(4 \mathrm{~m} / \mathrm{s})$ sharing $\mathrm{T}_{\mathrm{S}}$ of $95^{\circ} \mathrm{F}(308 \mathrm{~K})$.

Acceptable mixing was observed at $\mathrm{V}_{\mathrm{S}}$ of $329 \mathrm{fpm}(1.67 \mathrm{~m} / \mathrm{s})$ with some stratification layers within $2 \mathrm{ft}$ from the floor. This case had an ADPI of 0.65 . Increasing the velocity to $788 \mathrm{fpm}$ (4 $\mathrm{m} / \mathrm{s}$ ) provided a good mixing with an ADPI of 0.89 . The air circulation at this velocity was able to eliminate the room stratification and provide a higher level of comfort. 


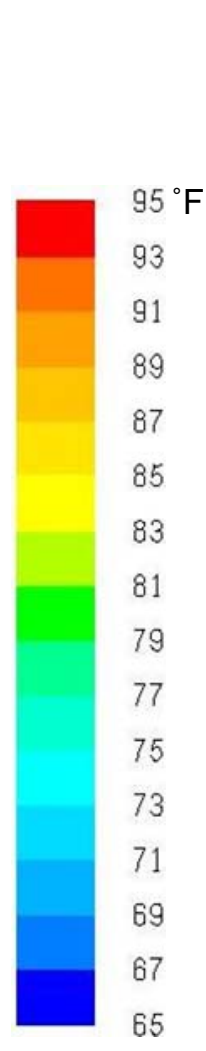

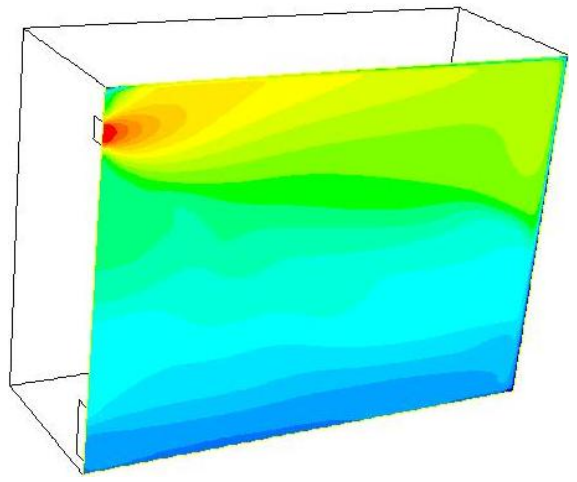

(a)

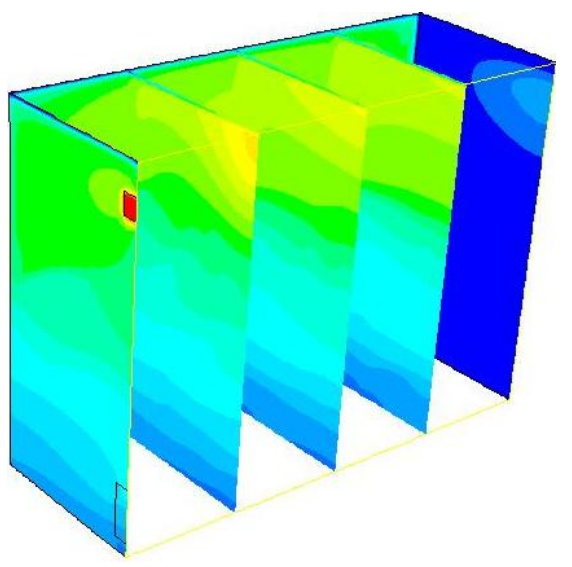

(a)

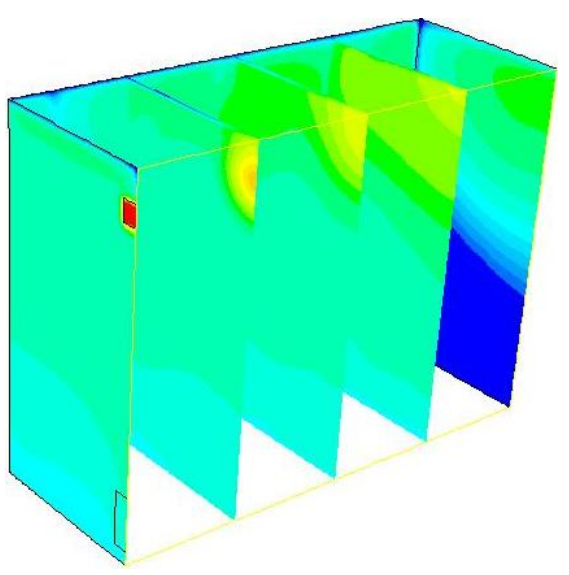

(b)

Figure 9. Temperature distribution in the room, with a 10×6 inlet, at 1 air change when supplied by $T_{s}$ of $95^{\circ} \mathrm{F}(308 \mathrm{~K})$ : (a) $\mathrm{V}_{\mathrm{s}}=329 \mathrm{fpm}(1.67 \mathrm{~m} / \mathrm{s})$ and $(\mathrm{b}) \mathrm{V}_{\mathrm{s}}=788 \mathrm{fpm}(4 \mathrm{~m} / \mathrm{s})$. Left plots are at the symmetry plane and right plots are at different cross sections throughout the room

\section{Cooling Mode}

Cooling mode simulations were performed on the same room as described in the previous subsection. All geometries and boundary conditions are the same, except that the peak thermal load density was set at $10 \mathrm{Btu} / \mathrm{ft}^{2} \cdot \mathrm{h}\left(31.52 \mathrm{~W} / \mathrm{m}^{2}\right)$ for cooling. Simulations presented here were started from an initial state of uniform room temperature of $80^{\circ} \mathrm{F}(299.8 \mathrm{~K})$. The thermostat setpoint was $71^{\circ}(294.82) \pm 1^{\circ} \mathrm{F}(0.56 \mathrm{~K})$. The results are given first for $8 \times 1$ then for $8 \times 4$ and $10 \times 6$ inlet sizes.

The performance of the smaller inlet $(8 \times 1)$ is presented in Figure 10, which shows the variations of air temperature near the thermostat and the supply velocity as a function of time for two supply velocities of $591 \mathrm{fpm}(3 \mathrm{~m} / \mathrm{s})$ and $788 \mathrm{fpm}(4 \mathrm{~m} / \mathrm{s})$. Both supply velocities share a temperature of $55^{\circ} \mathrm{F}(286 \mathrm{~K})$. We see two systems that are running continuously and, after 1 air change, the room air temperature continue to increase because of system capacities that are much smaller than the peak load. The velocity of $591 \mathrm{fpm}(3 \mathrm{~m} / \mathrm{s})$ corresponds to a $57 \%$ undersized system and $788 \mathrm{fpm}(4 \mathrm{~m} / \mathrm{s}$ ) corresponds to a $43 \%$ undersized system. Despite the good mixing 
observed in Figure 11 for these two conditions, the space is very uncomfortable with ADPIs of 0 for $591 \mathrm{fpm}(3 \mathrm{~m} / \mathrm{s})$ and 0.01 for $788 \mathrm{fpm}(4 \mathrm{~m} / \mathrm{s})$.
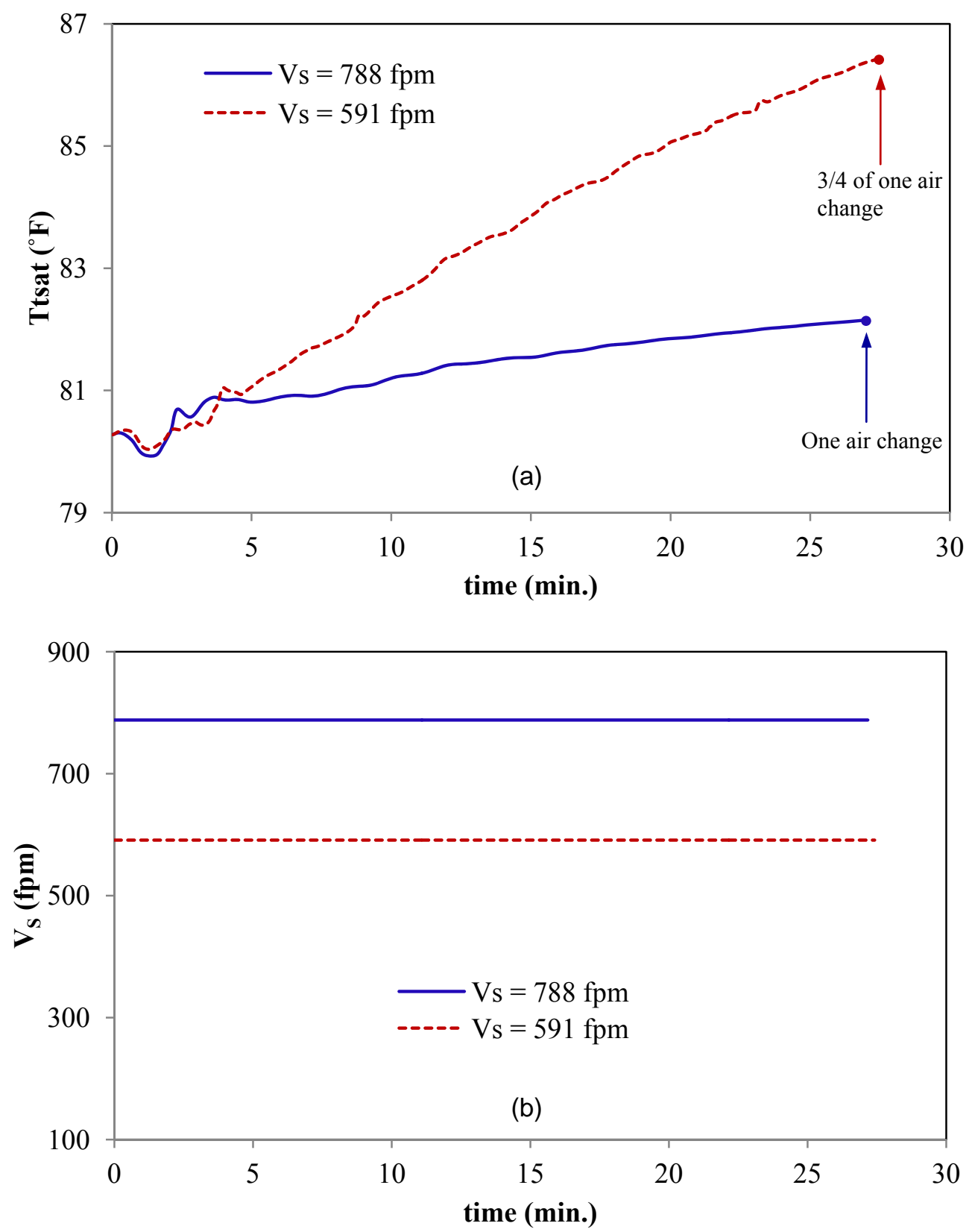

Figure 10. Temporal evolution of air temperature near the thermostat (a) and supply velocity at the inlet (b) of the room with $8 \times 1$ inlet when supplied by two different velocities, $591 \mathrm{fpm}(3 \mathrm{~m} / \mathrm{s})$ and $788 \mathrm{fpm}(4 \mathrm{~m} / \mathrm{s})$ with $T_{\mathrm{s}}=55^{\circ} \mathrm{F}(286 \mathrm{~K})$ 

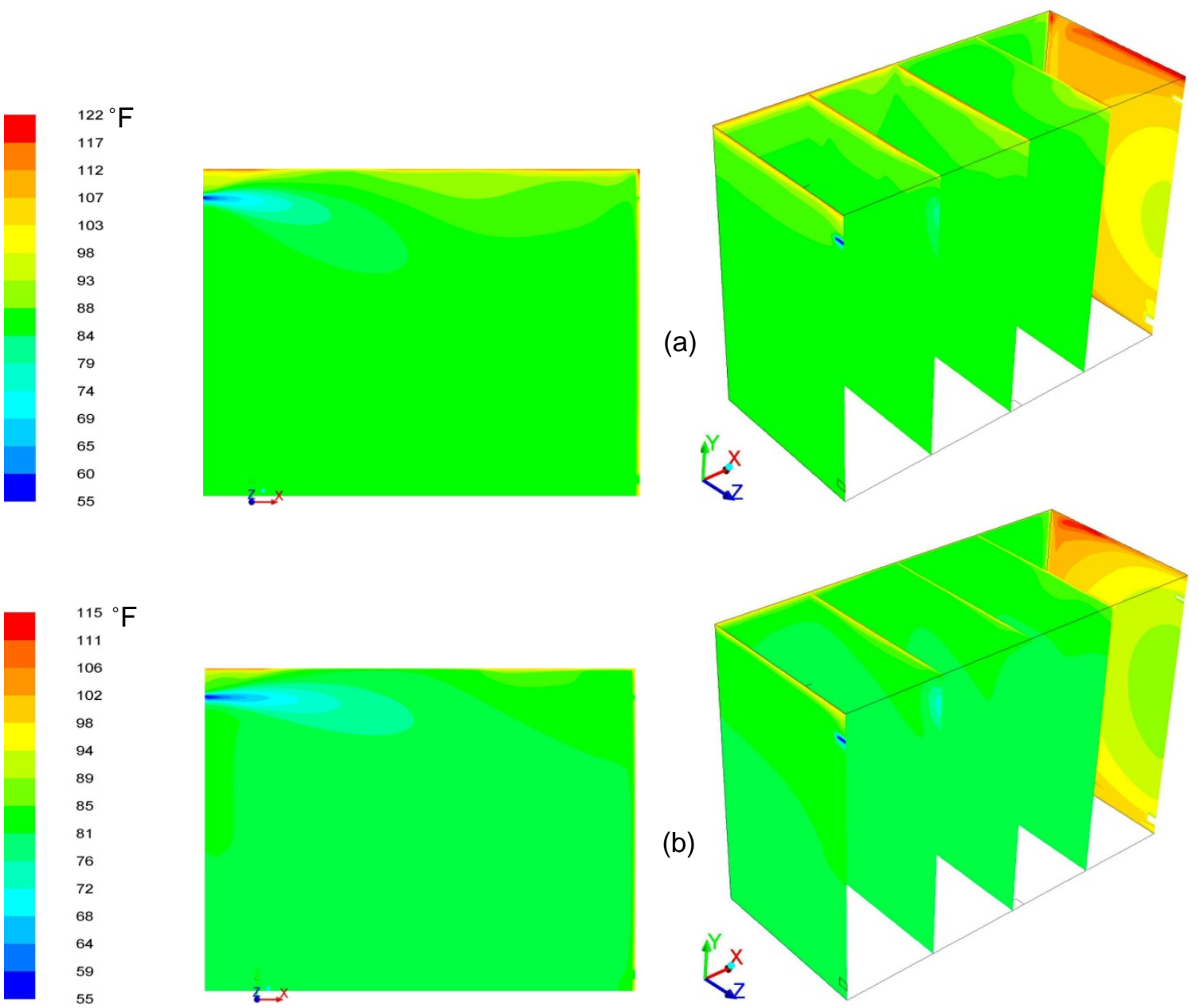

Figure 11. Temperature distribution in the room, with an $8 \times 1$ inlet, at 1 air change when supplied by $T_{s}$ of $55^{\circ} \mathrm{F}(286 \mathrm{~K})$ : (a) $V_{s}=591 \mathrm{fpm}(3 \mathrm{~m} / \mathrm{s})$ and (b) $V_{s}=788 \mathrm{fpm}(4 \mathrm{~m} / \mathrm{s})$. Left plots are at the symmetry plane and right plots are at different cross sections along the room

The time history of air temperature near the thermostat in the room, with an $8 \times 4$ inlet, supplied by $\mathrm{T}_{\mathrm{S}}$ of $55^{\circ} \mathrm{F}(285.9 \mathrm{~K})$ is presented in Figure 12(a) for two supply velocities. The corresponding velocity variations at the inlet are plotted in Figure 12(b). The time at which 1 air change was supplied to the room is marked on Figure 11(a). The air temperature decreased quickly with the supply velocity of $591 \mathrm{fpm}(3 \mathrm{~m} / \mathrm{s})$ and entered a quasi-steady state mode characterized by oscillation cycles around the thermostat set-point. A decrease in supply velocity to 394 fpm (2 $\mathrm{m} / \mathrm{s}$ ) delayed the room cooling and resulted in longer cooling cycles. The velocity of $394 \mathrm{fpm}(2$ $\mathrm{m} / \mathrm{s})$ corresponds to a $14 \%$ oversized system with an ADPI of 0.98 and $591 \mathrm{fpm}(3 \mathrm{~m} / \mathrm{s})$ corresponds to a $60 \%$ oversized system with an ADPI of 0.97 . 

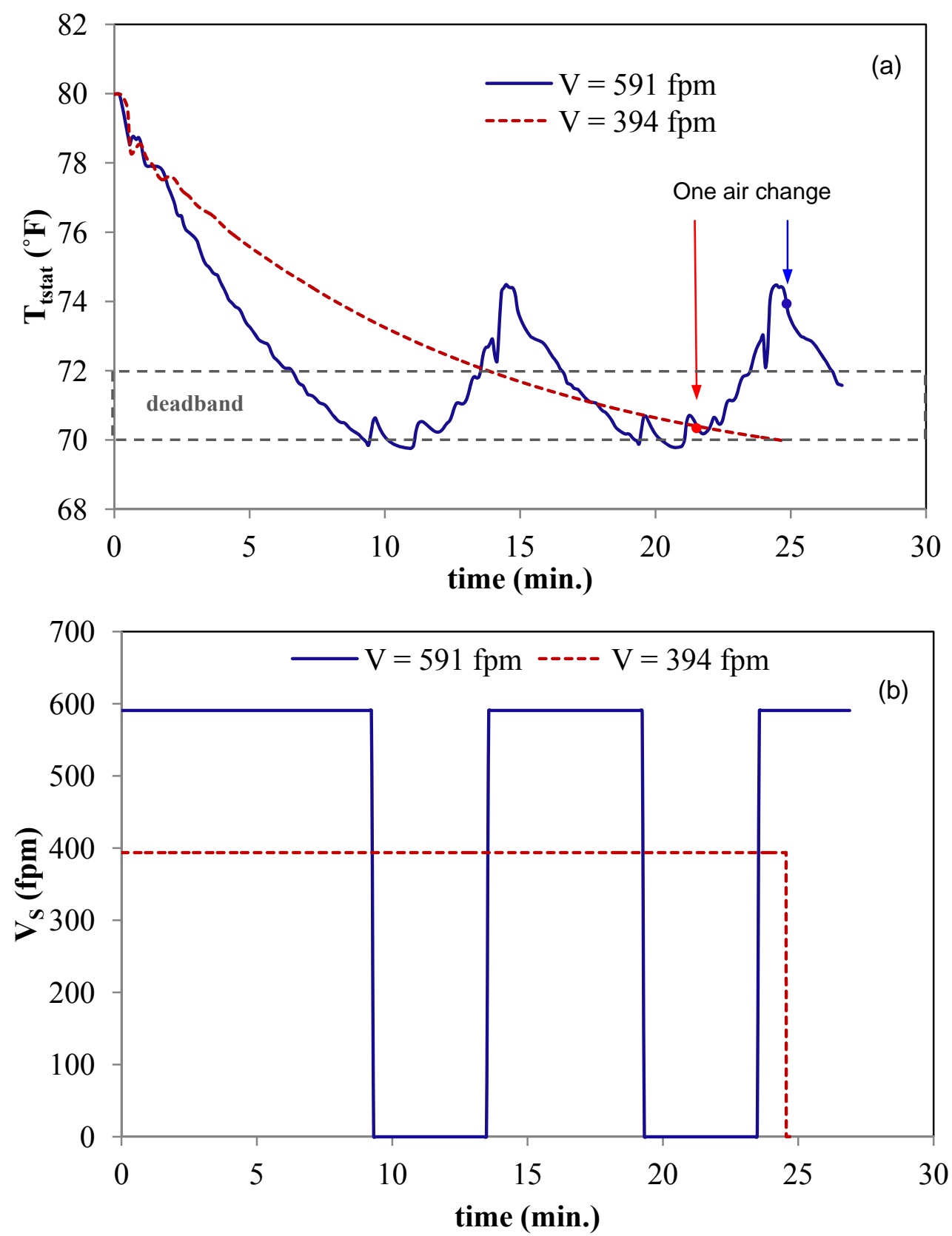

Figure 12. Temporal evolution of air temperature near the thermostat (a) and supply velocity at the inlet (b) of the room with $8 \times 4$ inlet when supplied by two different velocities, $394 \mathrm{fpm}(2 \mathrm{~m} / \mathrm{s})$ and $591 \mathrm{fpm}(3 \mathrm{~m} / \mathrm{s})$ with $\mathrm{T}_{\mathrm{s}}=55^{\circ} \mathrm{F}(286 \mathrm{~K})$

We are interested in the temporal evolution of the flow patterns during 1 air change. This is presented in Figure 13 in terms of the distribution of temperature corresponding to $\mathrm{V}_{\mathrm{S}}=788 \mathrm{fpm}$ $(4 \mathrm{~m} / \mathrm{s})$ and $\mathrm{T}_{\mathrm{S}}=55^{\circ} \mathrm{F}(285.9 \mathrm{~K})$. The contour plots are on the vertical mid-plane of symmetry at $25 \%, 50 \%, 75 \%$, and $100 \%$ of the time for 1 air change. The isotherms showed good mixing between the supply air and the room air. The jet was attached to the ceiling and mixed with the room air after hitting the opposite wall. Low supply velocities resulted in sinking jets, which may cause occupant discomfort. 


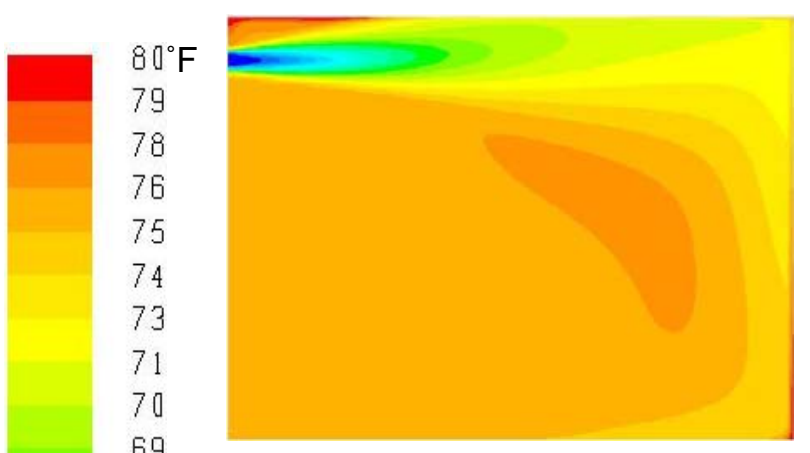

$25 \%$ of 1 air change

66

65

64

63

61

60

59

58

56

55

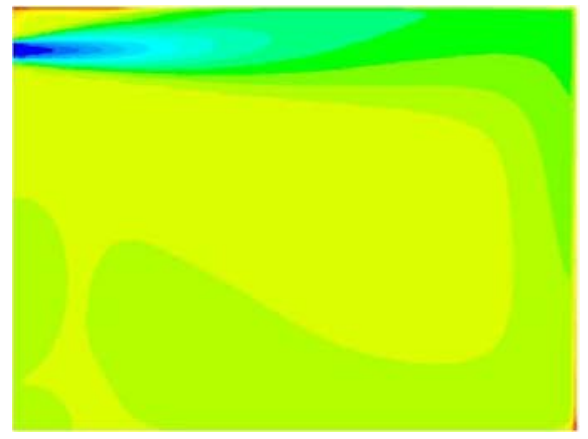

$75 \%$ of 1 air change

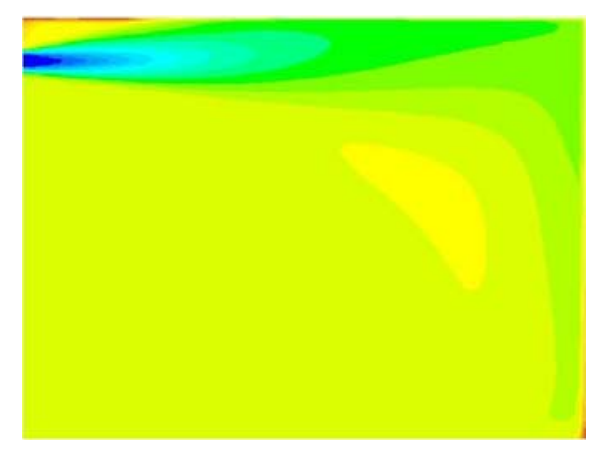

$50 \%$ of 1 air change

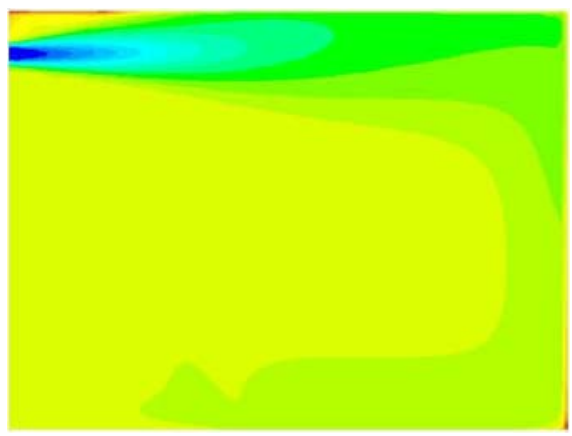

$100 \%$ of 1 air change

Figure 13. Temperature distribution at the symmetry plane of the room, with an $8 \times 4$ inlet, when $V_{s}$ $=788 \mathrm{fpm}(4 \mathrm{~m} / \mathrm{s})$ and $\mathrm{T}_{\mathrm{s}}=55^{\circ} \mathrm{F}(285.9 \mathrm{~K})$

A different view of the flow structure is illustrated in Figure 14 at selected cross sections along the room. This was at an intermediate supply velocity $V_{S}=591 \mathrm{fpm}(3 \mathrm{~m} / \mathrm{s})$. The left image was for $\mathrm{T}_{\mathrm{S}}=55^{\circ} \mathrm{F}(285.9 \mathrm{~K})$ and the right image was for $\mathrm{T}_{\mathrm{S}}=65^{\circ} \mathrm{F}(291.5 \mathrm{~K})$, both at 1 air change. The temperature fields showed well-mixed air with some hot regions near the ceiling and at the wall opposite to the air jet throw. These hot spots, which were caused by the peak load applied at these locations, were more intense at higher supply temperature of $65^{\circ} \mathrm{F}(291.5 \mathrm{~K})$. 


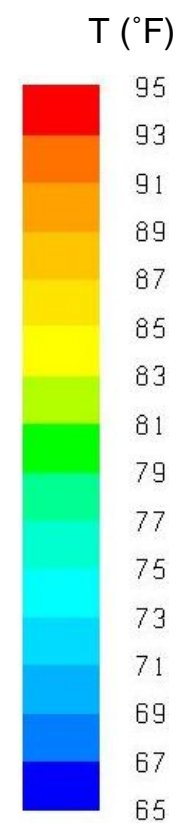

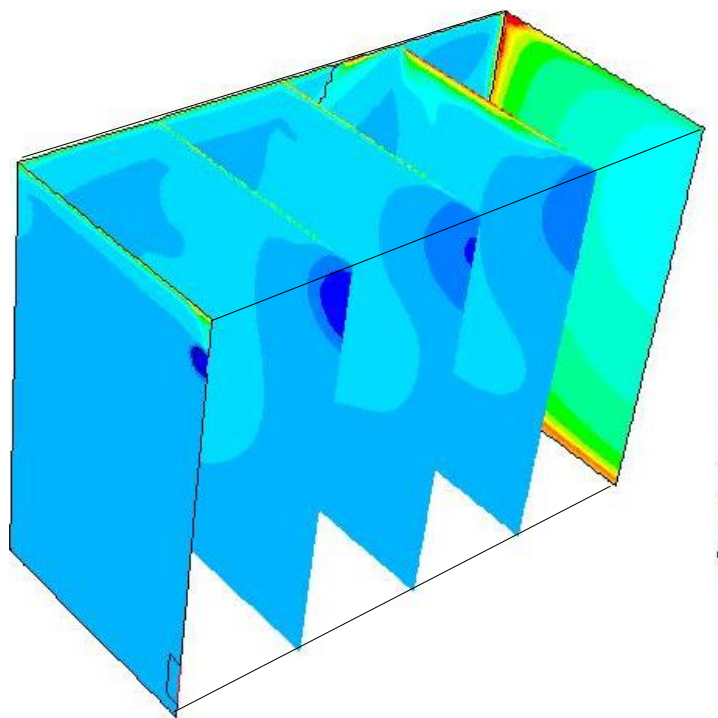

(a): $\mathrm{T}_{\mathrm{S}}=55^{\circ} \mathrm{F}(285.9 \mathrm{~K})$ $\mathrm{ADPI}=0.97$

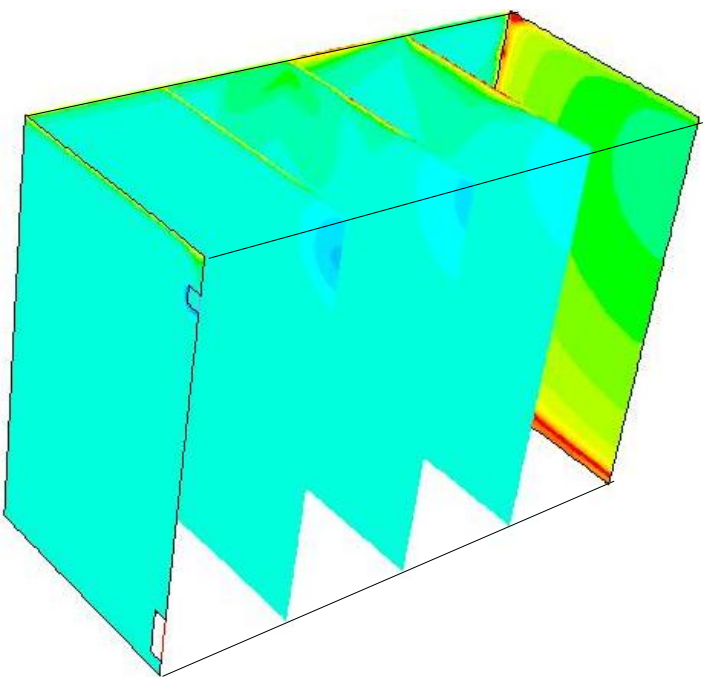

(b): $\mathrm{T}_{\mathrm{S}}=65^{\circ} \mathrm{F}(291.5 \mathrm{~K})$ $\mathrm{ADPI}=0.98$

Figure 14. Temperature distribution in the room, with an $8 \times 4$ inlet, at 1 air change when supplied by $V_{s}=591 \mathrm{fpm}(3 \mathrm{~m} / \mathrm{s}):(a) \mathrm{T}_{\mathrm{s}}=55^{\circ} \mathrm{F}(285.9 \mathrm{~K})$ and $(\mathrm{b}) \mathrm{T}_{\mathrm{s}}=65^{\circ} \mathrm{F}(291.5 \mathrm{~K})$

Figure 15 shows the plots of draft temperature at full scale on the top row and the plots of acceptable draft temperature, which is between $-3(-1.7)$ and $2^{\circ} \mathrm{F}(1.1 \mathrm{~K})$, on the bottom row. Three supply velocities of $394 \mathrm{fpm}(2 \mathrm{~m} / \mathrm{s}), 591 \mathrm{fpm}(3 \mathrm{~m} / \mathrm{s})$, and $788 \mathrm{fpm}(4 \mathrm{~m} / \mathrm{s})$ were tested and the ADPI was evaluated at one air change. The red line limits the height of the occupied zone. Regions of acceptable draft temperature are larger at low velocity and decrease as the velocity increases. As a result, the velocities of $394 \mathrm{fpm}(2 \mathrm{~m} / \mathrm{s})$ and $591 \mathrm{fpm}(3 \mathrm{~m} / \mathrm{s})$ provided acceptable occupant comfort with ADPIs of 0.97 and 0.92 , respectively. ADPI drops to 0.69 at a supply velocity of $788 \mathrm{fpm}(4 \mathrm{~m} / \mathrm{s})$ due to increase in drafts near the floor caused by the higher velocity supply. 


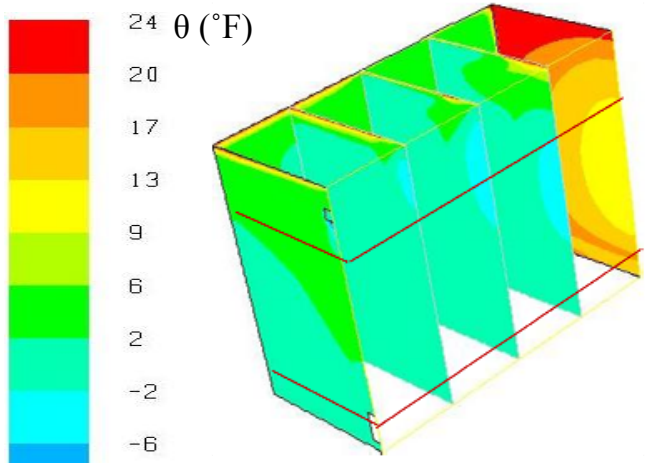

(a)

ADPI $=0.97$
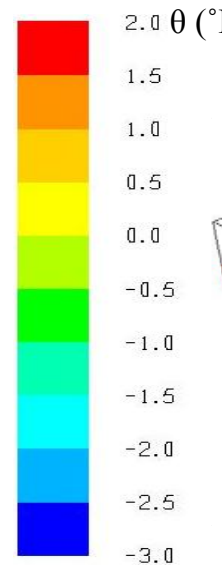

F)

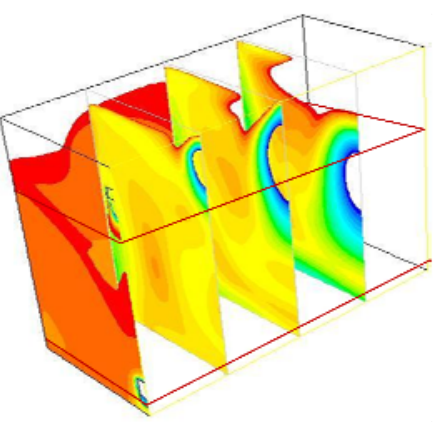

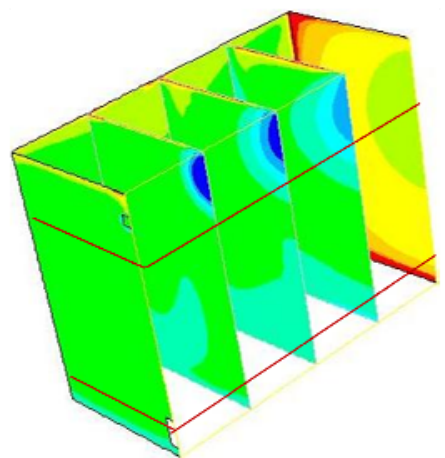

(b)

ADPI $=0.92$

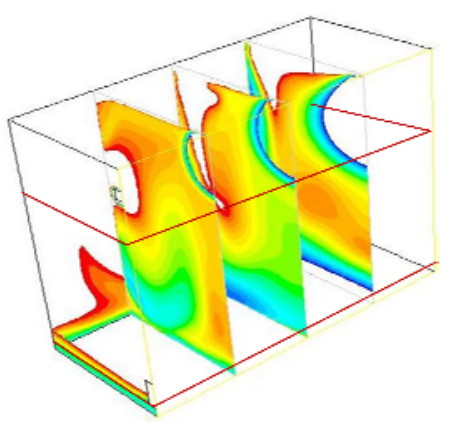

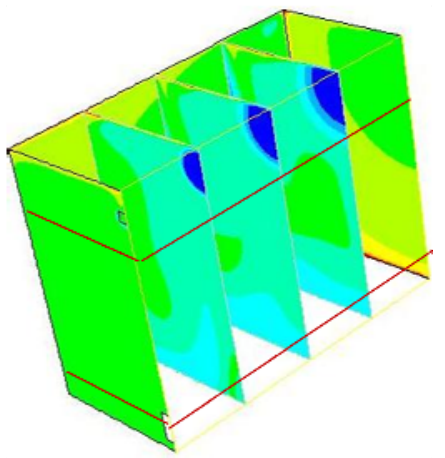

(c)

ADPI $=0.69$

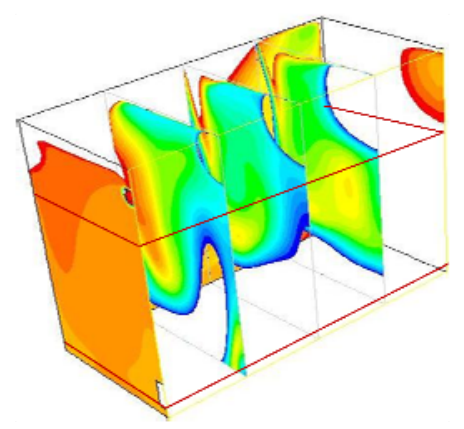

Figure 15. Distribution of draft temperature in the room, with an $8 \times 4$ inlet, when $\mathrm{T}_{\mathrm{S}}=55^{\circ} \mathrm{F}(285.9$

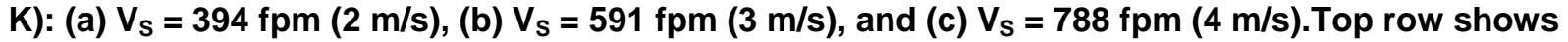
the draft temperature at full scale and the bottom row shows the acceptable draft temperature, between $-3(-1.7)$ and $2^{\circ} \mathrm{F}(1.1 \mathrm{~K})$.

The simulation results for the $10 \times 6$ supply inlet are discussed in the remainder of this section. This inlet is larger and, for a fixed supply velocity, 1 air change will be reached much faster than with an $8 \times 1$ or an $8 \times 4$ inlet.

Figure 16 shows the time history of air temperature near the thermostat with a supply velocity of $788 \mathrm{fpm}(4 \mathrm{~m} / \mathrm{s})$ for two supply air temperatures of $55^{\circ} \mathrm{F}(285.9 \mathrm{~K})$ and $65^{\circ} \mathrm{F}(291.5 \mathrm{~K})$. Both curves started at a high value of about $80^{\circ} \mathrm{F}(299.8 \mathrm{~K})$ and decreased monotonically with time to reach a minimum of about $70^{\circ} \mathrm{F}(294.3 \mathrm{~K})$ and then entered an oscillation mode as a result of thermostat control. The large temperature values at the start of the simulation were attributed to the initial condition of uniform room temperature of $80^{\circ} \mathrm{F}(299.8 \mathrm{~K})$. With a supply of $55^{\circ} \mathrm{F}$ $(285.9 \mathrm{~K})$, the system is $320 \%$ oversized and the room cooled quickly and stayed within the comfort zone set by the thermostat. However, with $65^{\circ} \mathrm{F}(291.5 \mathrm{~K})$ supply, the system is $61 \%$ 
oversized and the cooling took longer and for short periods of time, the room temperature went above the comfort zone.

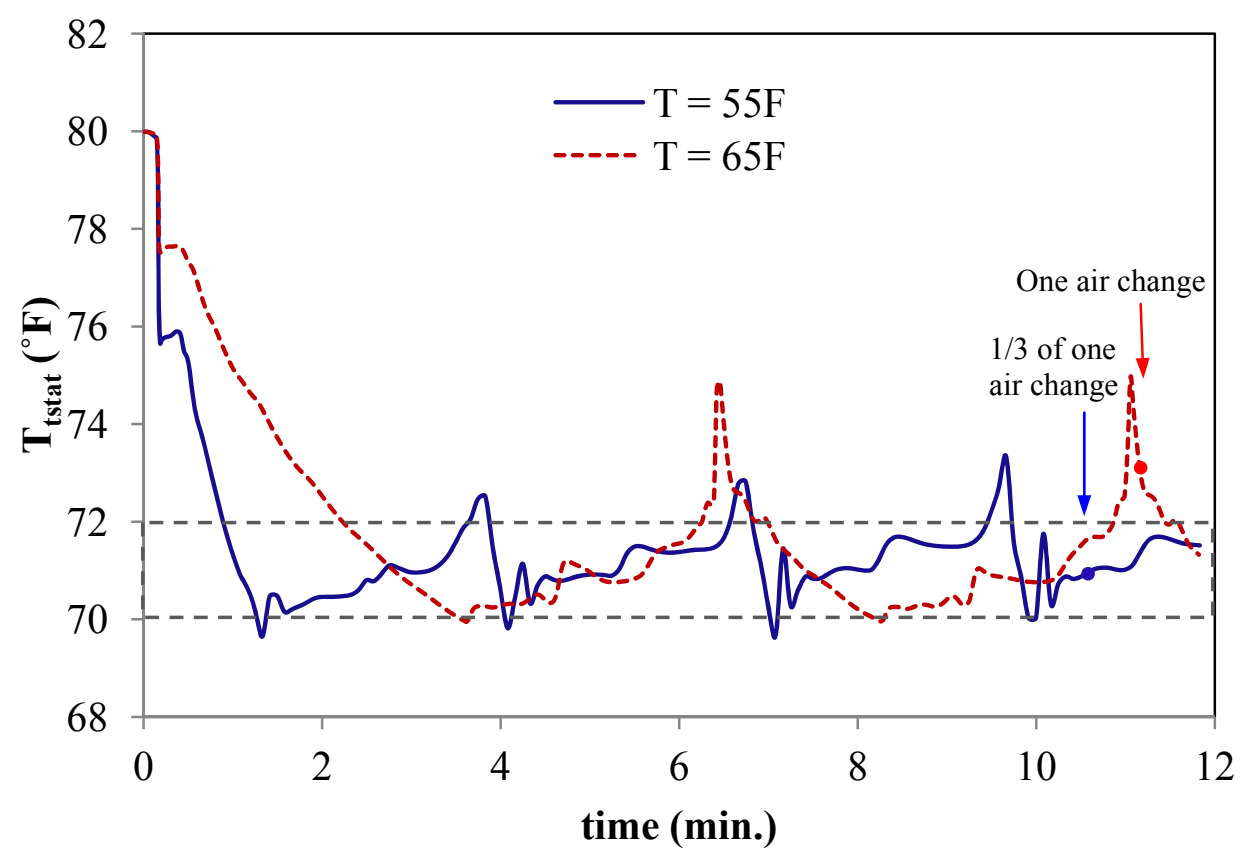

Figure 16. Temporal evolution of air temperature near the thermostat when the room is supplied by a $10 \times 6$ inlet at $V_{s}=788 \mathrm{fpm}(4 \mathrm{~m} / \mathrm{s})$

The flow visualization is presented in Figure 17 by the distributions of temperature and velocity at the symmetry plane of the room. Three velocities of $329 \mathrm{fpm}(2 \mathrm{~m} / \mathrm{s}), 558 \mathrm{fpm}(3 \mathrm{~m} / \mathrm{s})$, and $788 \mathrm{fpm}(4 \mathrm{~m} / \mathrm{s})$ supplying $55^{\circ} \mathrm{F}(285.9 \mathrm{~K})$ air were considered. At low velocity of $394 \mathrm{fpm}(2$ $\mathrm{m} / \mathrm{s}$ ), the air jet lost momentum toward the middle of the room and sank into the occupied zone, which may cause occupant discomfort. A different scenario was observed at $558 \mathrm{fpm}(2.83 \mathrm{~m} / \mathrm{s})$ and $788 \mathrm{fpm}(4 \mathrm{~m} / \mathrm{s})$, where the jet had enough momentum to cross the room and circulate along the wall. Better mixing occurred at the higher velocity of $788 \mathrm{fpm}(4 \mathrm{~m} / \mathrm{s})$, as depicted by the velocity vectors in Figure 17(d). 


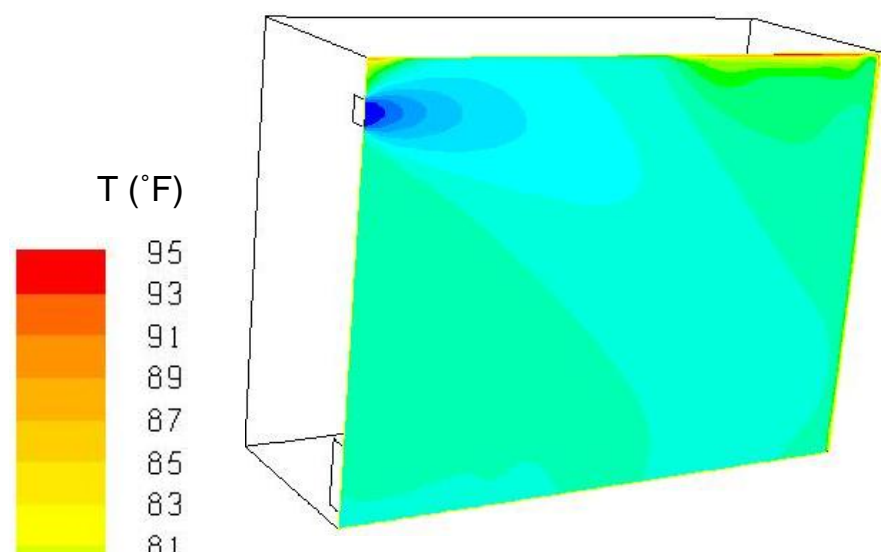

(a)

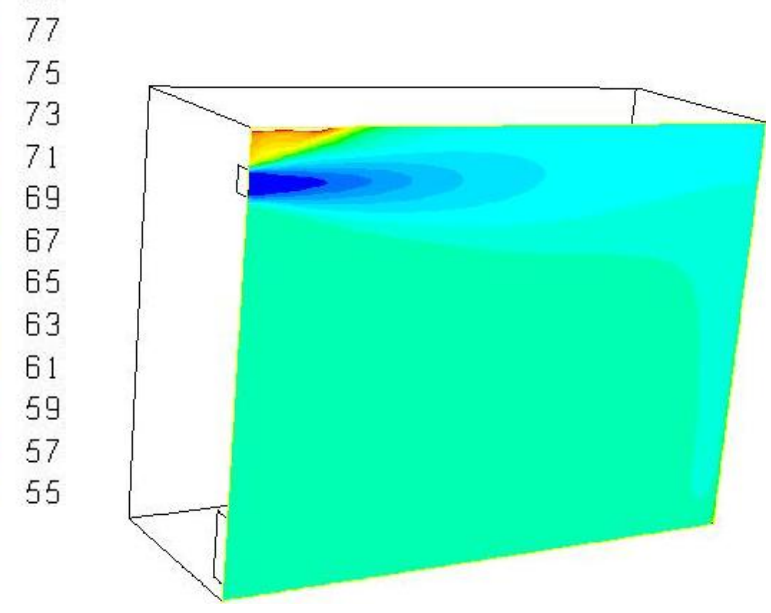

(c)

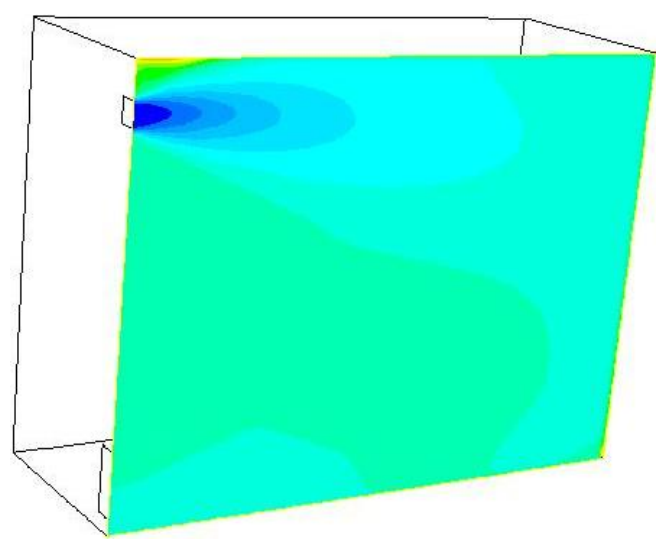

(b)

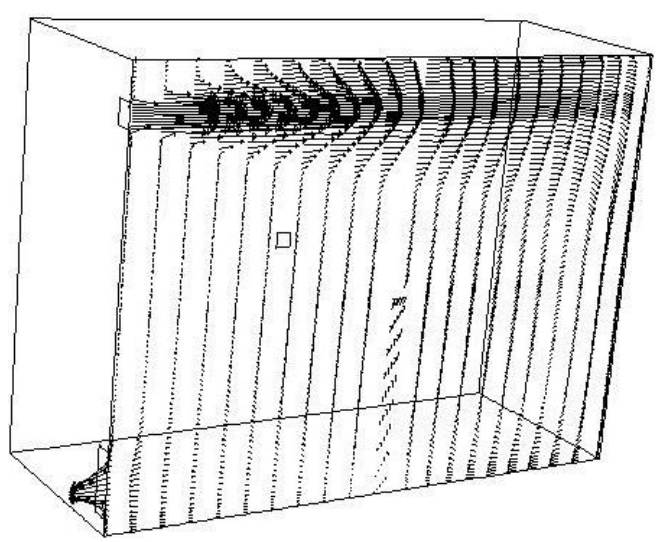

(d)

Figure 17. Temperature distribution (a-c) and velocity vectors (d) at the symmetry plan of the room, with a $10 \times 6$ inlet: (a) $V_{s}=329 \mathrm{fpm}(1.67 \mathrm{~m} / \mathrm{s})$, (b) $V_{s}=558 \mathrm{fpm}(2.83 \mathrm{~m} / \mathrm{s})$, and (c-d) $V_{s}=788$ $\mathrm{fpm}(4 \mathrm{~m} / \mathrm{s})$. The supply temperature is $55^{\circ} \mathrm{F}(285.9 \mathrm{~K})$. 


\section{Conclusions}

The performance of high sidewall air supply systems in perimeter zones of residential applications was studied through numerical simulations using computational fluid dynamics modeling. We simulated three air inlet jets in the $8 \times 1,8 \times 4$ and $10 \times 6$ sizes over a wide range of operating conditions. Parameters were the supply temperature, supply velocity, and inlet size. Model output was used to determine how well the supply air mixes with the room air and quantify the comfort level using ADPI. The room has an acceptable ADPI level when its value is greater than 0.7. System operation with ADPI below 0.7 is not recommended. The results summarized in this section provide the end point system performance information required to optimize overall space conditioning system design.

\section{Heating Mode}

Figure 18 shows the capacity of different systems considered relative to the peak load for each inlet size. The peak load was fixed and system capacity was varied with supply velocity and supply temperature. For the conditions considered in the current study, the $8 \times 1$ inlet provides the best match to peak load. Larger inlets in the $8 \times 4$ and $10 \times 6$ sizes provide much higher loads at intermediate and high supply velocities. Cost would be expected to be a practical constraint for systems supplying loads in the gray areas of Figure 18. These points were included to show full range of ADPI trends.

(c) $8 \times 1$ inlet

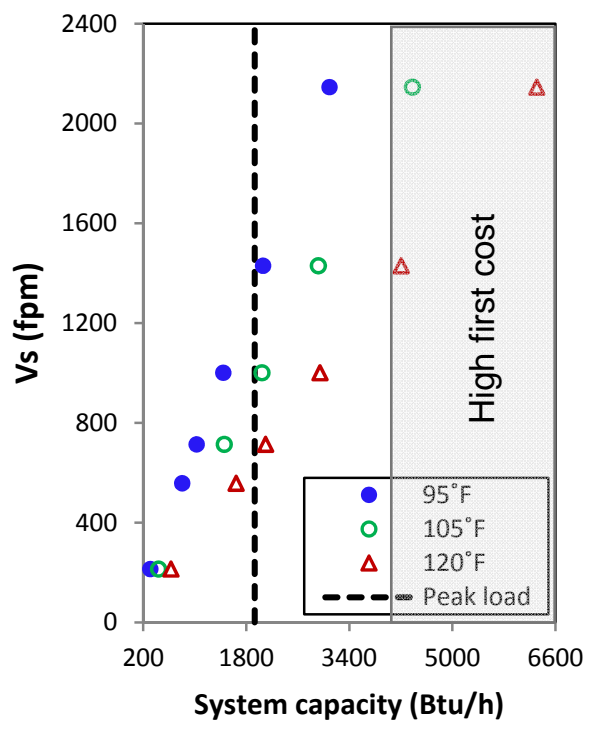

(a) $8 \times 4$ inlet

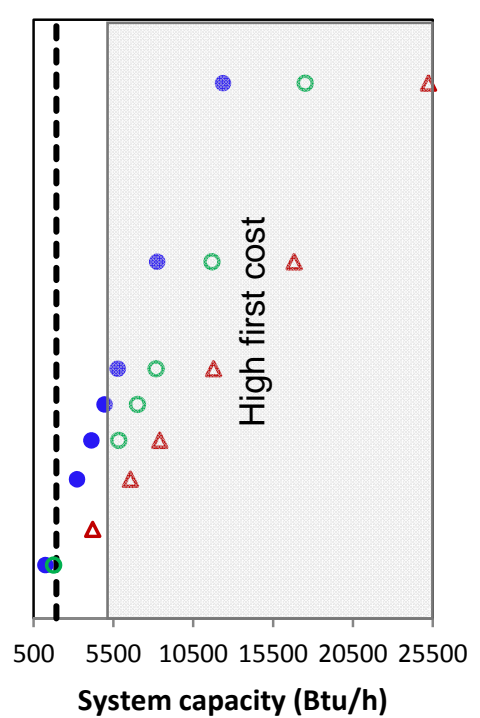

(b) $10 \times 6$ inlet

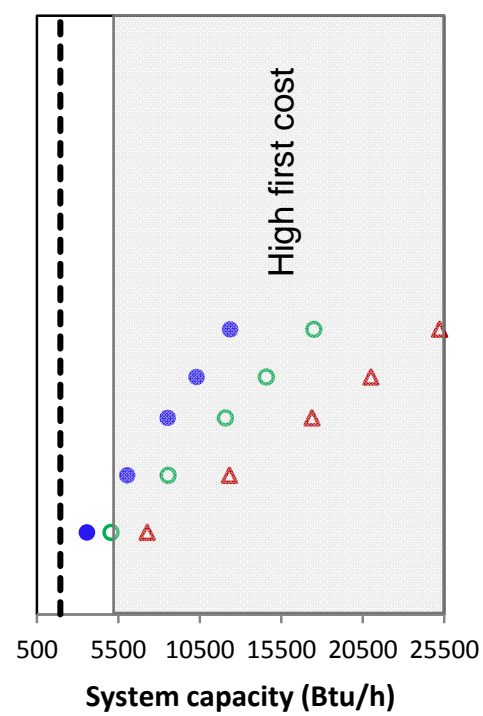

Figure 18. Capacity of different systems relative to peak load in heating mode: (a) $8 \times 1$ inlet, (b) $8 \times 4$ inlet, and (c) $10 \times 6$ inlet.

The effect of thermostatic control and peak load on the mixing behavior of each inlet is summarized in Figure 19 by the variations of ADPI as a function of supply velocity. The figure shows that ADPI started with low values at low velocities. As the mixing improved due to higher 
supply velocities, ADPI increased and reached a maximum at low and intermediate supply temperatures of $95^{\circ} \mathrm{F}(308 \mathrm{~K})$ and $105^{\circ} \mathrm{F}(314 \mathrm{~K})$ and decreased at high supply velocities. The reduction in ADPI is due to drafts at high supply velocities. ADPI results for $95^{\circ} \mathrm{F}(308 \mathrm{~K})$ and $105^{\circ} \mathrm{F}(314 \mathrm{~K})$ supply temperatures show a fairly broad range of acceptable ADPI at lower supply velocities than can be achieved at $120^{\circ} \mathrm{F}(322 \mathrm{~K})$ supply temperatures. For the high supply temperature of $120^{\circ} \mathrm{F}(322 \mathrm{~K})$, ADPI continued to increase with supply velocity for all inlet sizes. At this high temperature, even higher supply velocities were required to overcome buoyancy effects and reach a good mixing in the room.

The smaller inlet of $8 \times 1$ with low and intermediate supply temperatures of $95^{\circ} \mathrm{F}(308 \mathrm{~K})$ and $105^{\circ} \mathrm{F}(314 \mathrm{~K})$ provided acceptable ADPI at low system capacities (low fan powers). The intermediate $(8 \times 4)$ and large $(10 \times 6)$ inlets required higher fan powers to reach the acceptable ADPIs.

(a) $8 \times 1$ inlet

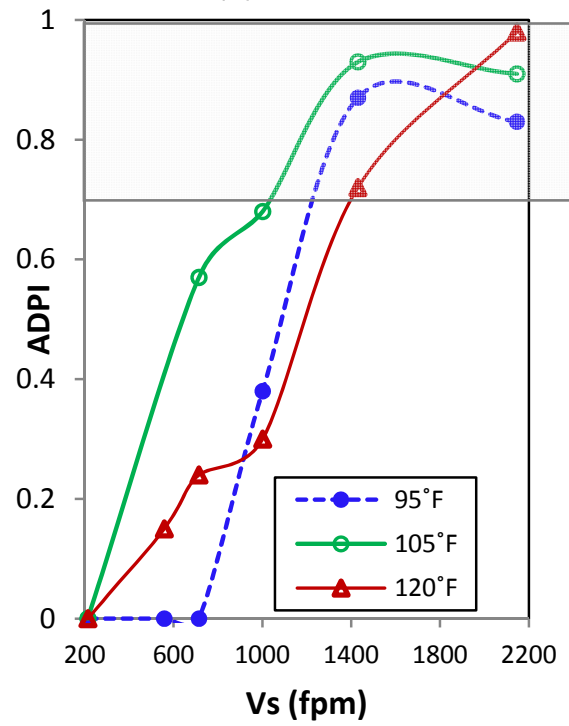

(b) $8 \times 4$ inlet

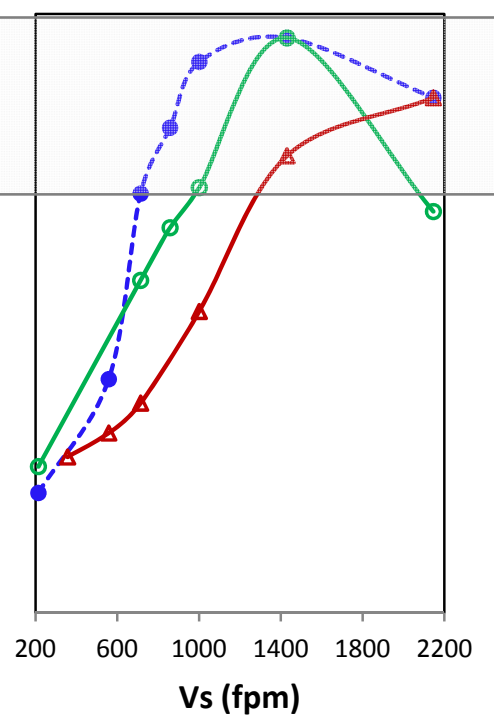

(c) $10 \times 6$ inlet

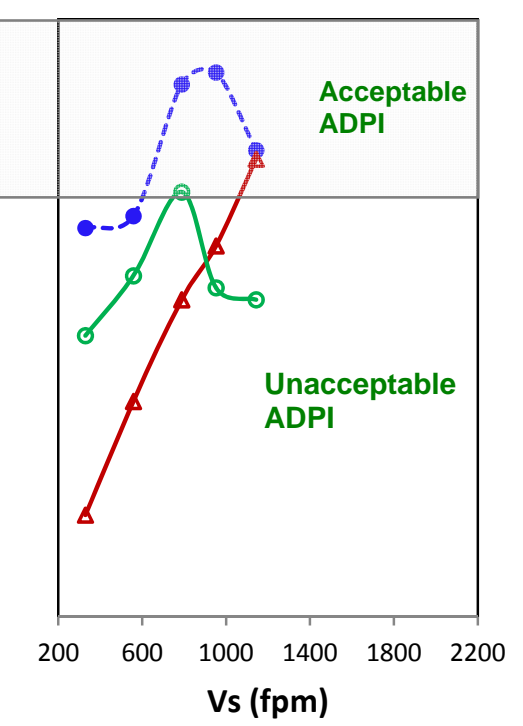

Figure 19. Variations of ADPI as a function of supply velocity in heating mode: (a) $8 \times 1$ inlet, (b) $8 \times 4$ inlet, and (c) $10 \times 6$ inlet.

\section{Cooling Mode}

A wide range of supply velocities was simulated to evaluate the performance of high sidewall air inlets in cooling mode. The air entered the room at $55^{\circ} \mathrm{F}(286 \mathrm{~K})$ or at $65^{\circ} \mathrm{F}(291 \mathrm{~K})$ and, with a relatively higher density, mixed easily with the room air. This is clearly seen in the plots of temperature distribution for all inlet sizes considered.

Figure 20 presents the capacity of different systems considered relative to the peak load for each inlet size. The peak load was fixed and system capacity was varied with supply velocity and supply temperature. Undersized and properly sized systems were able to achieve acceptable ADPI levels (see Figure 21 ). For the smaller inlet of $8 \times 1$ supplying $55^{\circ} \mathrm{F}(286 \mathrm{~K})$ air, the highest supply velocity of $1500 \mathrm{fpm}(7.61 \mathrm{~m} / \mathrm{s})$ led to a $9 \%$ oversized system. The supply temperature of 
$65^{\circ} \mathrm{F}(291 \mathrm{~K})$ was unable to meet the peak load: a high velocity of $1500 \mathrm{fpm}(7.61 \mathrm{~m} / \mathrm{s})$ led to a $59 \%$ undersized system and for this reason the results of $65^{\circ} \mathrm{F}(291 \mathrm{~K})$ are not presented. Here again the first cost is expected to be a practical constraint for systems supplying loads in the gray areas of Figure 20. These points were included to show full range of ADPI trends.

(a) $8 \times 1$ inlet

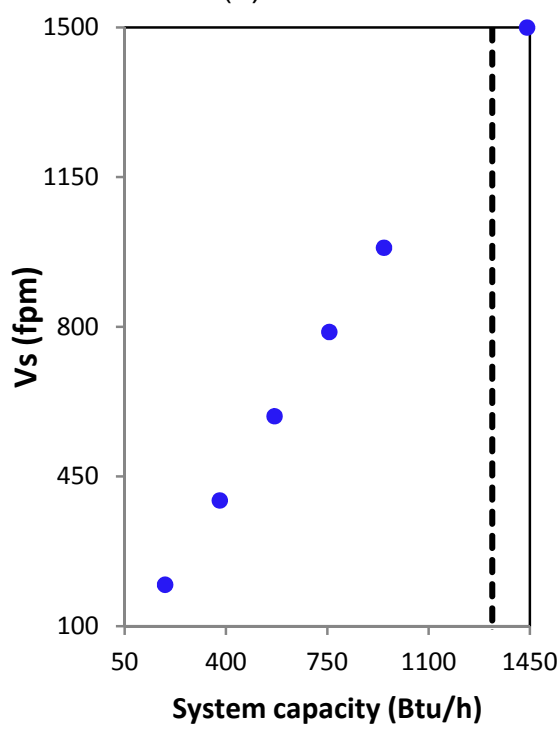

(c) $8 \times 4$ inlet

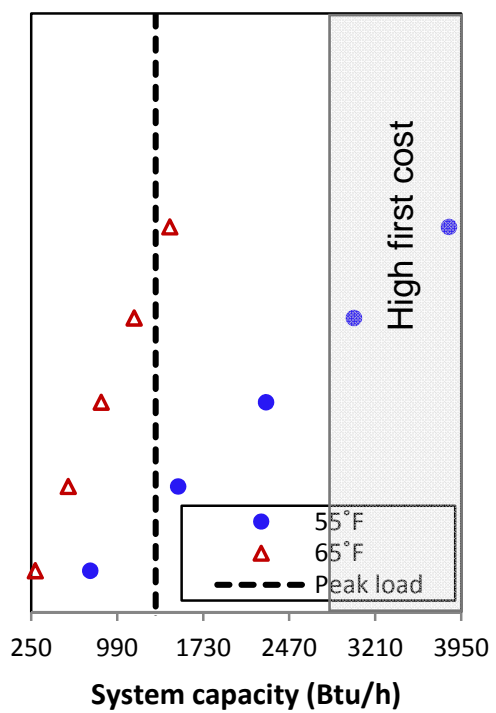

(b) $10 \times 6$ inlet

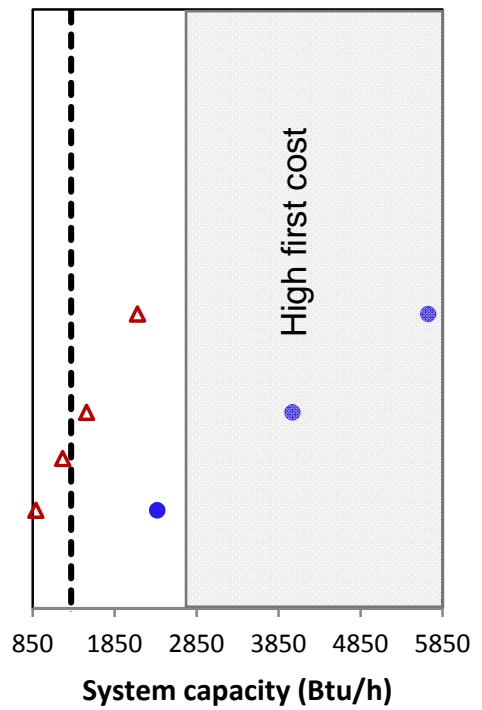

Figure 20. Capacity of different systems relative to peak load in cooling mode: (a) $8 \times 1$ inlet, (b) $8 \times 4$ inlet, and (c) $10 \times 6$ inlet.

Figure 21 illustrates the variations of ADPI with system operating conditions. Compared to the heating mode, similar trends were observed in cooling mode, except for the larger inlet (Figure 21(c)) for which ADPI started at high values of about 1 and stayed almost constant at low velocities. The graph for the intermediate inlet of $8 \times 4$ shows that ADPI increased with the velocity, passed through a maximum, and dropped at high velocities due to increase in drafts caused by higher velocities. For system capacities below the peak load, the smaller inlet of $8 \times 1$ was unable to reach acceptable ADPI levels. Out of all system capacities analyzed for this inlet size only one, which is $9 \%$ higher that the peak load, provided acceptable ADPI for the room. 
(a) $8 \times 1$ inlet

(b) $8 \times 4$ inlet

(c) $10 \times 6$ inlet

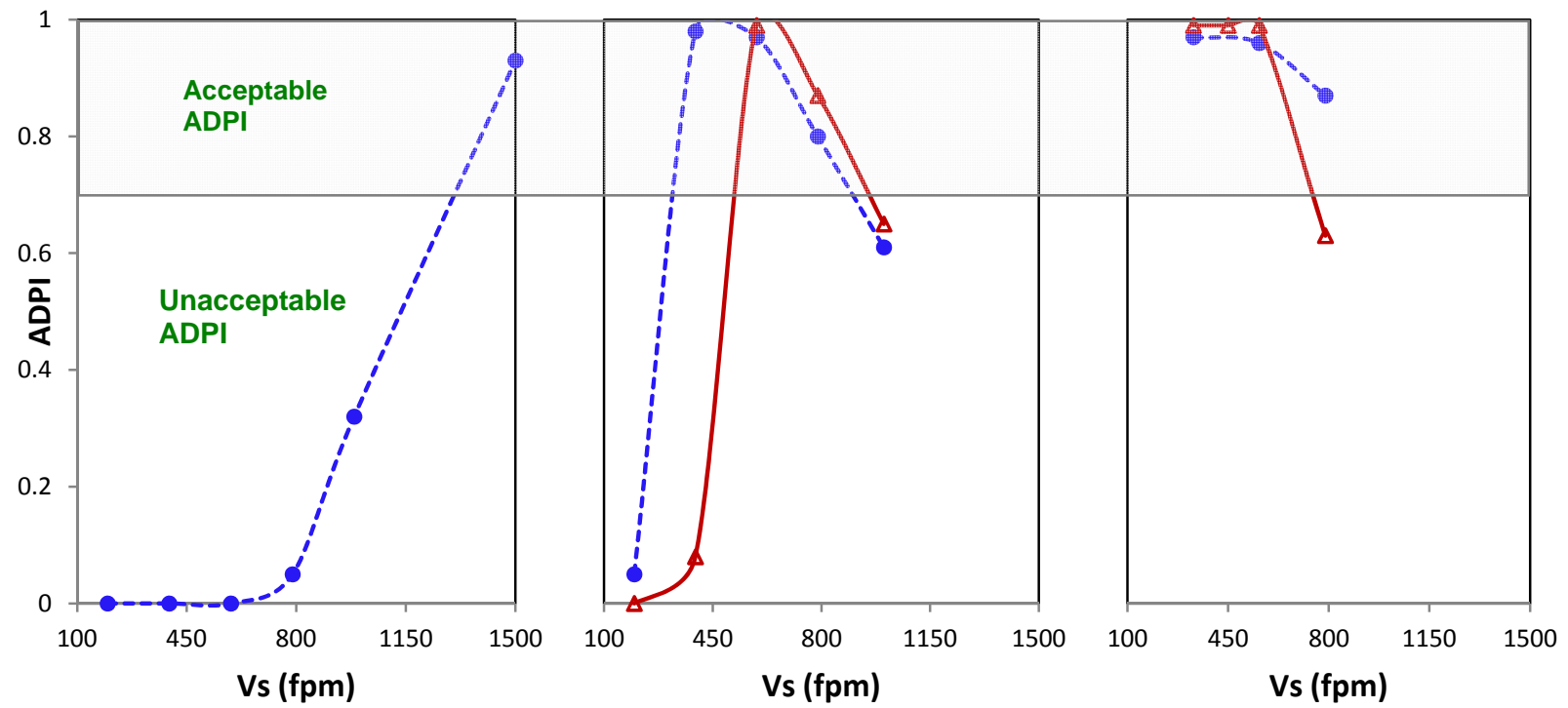

Figure 21. Variations of ADPI as a function of supply velocity in cooling mode: (a) $8 \times 1$ inlet, (b) $8 \times 4$ inlet, and (c) $10 \times 6$ inlet.

The trends of ADPI observed in Figures 19 and 21 are directly related to buoyancy effect. In heating, the supply air tends to rise, so high supply velocities were needed to provide good mixing. Higher supply temperature of $120^{\circ} \mathrm{F}(322 \mathrm{~K})$ led to stronger stratification and required higher supply velocities to reach acceptable ADPI levels. In cooling, however, the supply air with a higher density easily mixed with the room air. Low values of ADPI obtained at low supply velocities for $8 \times 1$ and $8 \times 4$ inlets are due to undersized systems with capacities much lower than the peak load. Despite the good mixing at high velocities, with oversized systems, the ADPI of $8 \times 4$ and $10 \times 6$ decreased because of drafts.

In summary, high sidewall air jets were proven to achieve uniform mixing in the room and provide acceptable levels of ADPI for specific operating conditions. Table B lists the recommended operating conditions and their corresponding fan powers for high sidewall inlet sizes analyzed in this study. These conditions led to acceptable ADPIs greater than 0.7 .

Table B. Recommended System Operating Conditions

\begin{tabular}{|l|c|c|c|c|c|c|}
\hline Inlet size (in. $^{2}$ ) & \multicolumn{2}{|c|}{$\mathbf{8} \times \mathbf{1}$} & \multicolumn{2}{c|}{$\mathbf{8} \times \mathbf{4}$} & \multicolumn{2}{c|}{$\mathbf{1 0 \times 6}$} \\
\hline Operating mode & Heating & Cooling & Heating & Cooling & Heating & Cooling \\
\hline Supply temperature $\left({ }^{\circ} \mathrm{F}\right)$ & 105 & 55 & 95 & 55 & 95 & $55-65$ \\
\hline Supply velocity $(\mathrm{fpm})$ & $1000-2146$ & 1500 & $714-1430$ & $394-788$ & $788-952$ & $329-558$ \\
\hline Fan power $(\mathrm{W})$ & $20-43$ & 30 & $57-115$ & $31-63$ & $119-144$ & $50-84$ \\
\hline
\end{tabular}




\section{References}

ACCA, Manual D (1995). Residential Duct Systems. Air Conditioning Contractors of America, Washington, D.C.

ACCA, Manual T (1992). Air Distribution Basics for Residential and Small Commercial Buildings. Air Conditioning Contractors of America, Washington, D.C.

ASHRAE. (2009). ASHRAE Fundamentals Handbook, 2009 IP Edition, Atlanta, GA, p. 20.13.

ASHRAE. (2010). ASHRAE Standard 55 - 2010. Thermal Environmental Conditions for Human Occupancy, Atlanta, GA.

Chen, Q.; Jiang, Z. (1992). Significant Questions in Predicting Room Air Motion, AN-92-9-1, ASHRAE Transactions: Symposia, pp. 929-939.

Chen, Q. (2009). Ventilation Performance Prediction for Buildings: A Method Overview and Recent Applications. Building and Environment, vol. 44, pp. 848-858.

Chow, W.K.; Wong, L.T. (1994). Experimental Studies on Air Diffusion of a Linear Diffuser and Associated Thermal Comfort Indices in an Air-conditioned Space. Building and Environment, vol. 29 (4), pp. 523-530.

Christensen, C.; Anderson, R.; Horowitz, S.; Courtney, A.; Spencer, J. (2006). BEopt(TM) Software for Building Energy Optimization: Features and Capabilities. NREL/TP-550-39929. Golden, CO: National Renewable Energy Laboratory.

Chung, K.C.; Lee, C.Y. (1996). Predicting Air Flow and Thermal Comfort in an Indoor Environment under Different Air Diffusion Models. Building and Environment, vol. 31 (1), pp. 21-26.

Corgnati, S.P.; Fracastro, G.V.; Nielsen, P.V.; Perino, M. (2002). Jet Drop and Draft Risk in a Mixing Ventilation Office Experimental and Numerical Investigation. In: Proceedings of ROOMVENT $8^{\text {th }}$ International Conference, Copenhagen, Denmark.

Corgnati, S.P.; Perino, M.; Fracastro, G.V.; Nielsen, P.V. (2009). Experimental and Numerical Analysis of Air and Radiant Cooling Systems in offices. Building and Environment, vol. 44, pp. 801-806.

FLUENT Manual, FLUENT Inc. (2006). 10 Cavendish Court, Centerra Resource Park, Lebanon, NH 03766, USA.

Hendron, R.; Engebrecht, C. 2010. Building America House Simulation Protocols. Building America Internal Report. Golden, CO: National Renewable Energy Laboratory.

Jalalzadeh, A.A.; Hancock, E.; Powell, D. (2007). Experimental Evaluation of Indoor Air Distribution in High-Performance Residential Buildings: Part I. General Descriptions and Qualification Tests. NREL/ TP-550-40392, 2007. Golden, CO: National Renewable Energy Laboratory.

Lam, J.C.; Chan, A.L.S. (2001). CFD Analysis and Energy Simulation of a Gymnasium. Building and Environment, vol. 36, pp. 351-358.

Norton, T.; Sun, D-W. (2006). Computational Fluid Dynamics (CFD) - An Effective and Efficient Design and Analysis Tool for the Food Industry: A Review. Trends in Food Science and Technology, vol. 17, pp. 600-620. 
Norton, T., Sun, D-W.; Grant, J.; Fallon, R.; Dodd, V. (2007). Applications of Computational Fluid Dynamics (CFD) in the Modeling and Design of Ventilation Systems in the Agricultural Industry: A Review. Bioresource Technology, vol. 98(12), pp. 2386-2414.

Wang, L.; Chen, Q. (2007). Theoretical and Numerical Studies of Coupling Multizone and CFD Models for Building Air Distribution Simulations. Indoor Air, vol. 17(5), pp. 348-361.

Yu, H.; Liao, C-M.; Liang, H-M.; Chiang, K-C. (2007). Scale Model Study of Airflow Performance in a Ceiling Slot-ventilated Enclosure: Non-isothermal Condition. Building and Environment, vol. 42 (3), pp. 1142-1150.

Zhang, Z.; Chen, X.; Mazumdar, S.; Zhang, T.; Chen. Q. (2009). Experimental and Numerical Investigation of Airflow and Contaminant Transport in an Airliner Cabin Mockup. Building and Environment, vol. 44 (1), pp. 85-94. 